
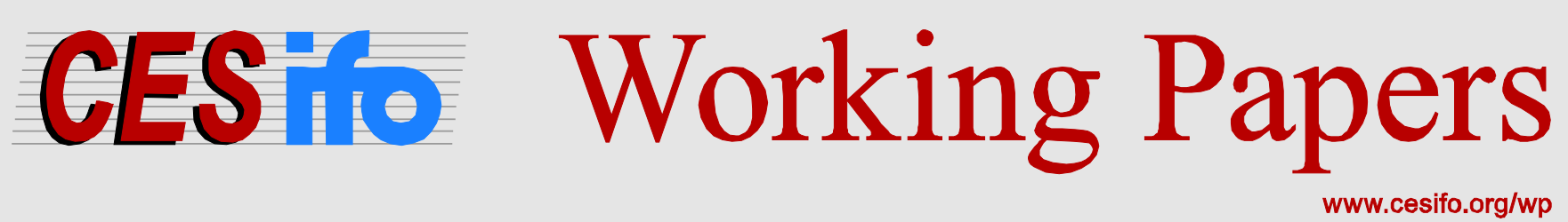

\title{
A Spatial Approach to Energy Economics: Theory, Measurement and Empirics
}

\author{
Juan Moreno-Cruz \\ M. Scott Taylor
}

\author{
CESIFO WORKING PAPER NO. 4845 \\ CATEGORY 9: RESOURCE AND ENVIRONMENT ECONOMICS \\ JUNE 2014
}

An electronic version of the paper may be downloaded

- from the SSRN website:

- from the RePEc website:

- from the CESifo website:

WwW.SSRN.com

Www.RePEc.org

www.CESifo-group.org/wp

\section{CESifo}




\title{
A Spatial Approach to Energy Economics: Theory, Measurement and Empirics
}

\begin{abstract}
This paper sets out a simple spatial model of energy exploitation to ask how the location and productivity of energy resources may affect the distribution of economic activity around the globe. We combine elements from resource and energy economics into one framework linking the spatial productivity of energy resources (both renewable and non-renewable) to the incentives for economic activity to concentrate. Our theory provides a novel scaling law; a magnification effect; and reveals a complementarity between infrastructure investment and spatially productive energy resources. Our empirical work provides estimates of key magnitudes and reviews empirical work supporting our approach.
\end{abstract}

JEL-Code: N500.

Keywords: energy economics, agglomeration, economic geography.

\author{
Juan Moreno-Cruz \\ School of Economics \\ Georgia Institute of Technology \\ USA - 30332 Atlanta / Georgia \\ juan.moreno-cruz@econ.gatech.edu
}

\author{
M. Scott Taylor \\ Department of Economics \\ University of Calgary \\ Canada - T2N 1N4 Calgary / Alberta \\ mstaylor@ucalgary.ca
}

June 9, 2014

Moreno-Cruz, Assistant Professor, School of Economics, Georgia Institute of Technology, Atlanta, Georgia; Taylor, Professor of Economics and Canada Research Chair, Department of Economics, University of Calgary, Canada and Research Associate at the NBER. In addition, Taylor is a fellow of the Beijer Institute of Ecological Economics and a CESifo associate and a research professor at the Ifo Institute, Germany. We are very grateful to seminar participants in several countries, and for the hospitality of the Energy Institute at Haas, University of California Berkeley and the Henri Poincare Institute in Paris, France where a portion of this work was conducted. We would like to thank, without implicating, Bob Allen, John Boyce, Jared Carbone, Oded Galor, Gene Grossman, David Laband, Arvind Magesan, Ken McKenzie, and Jim Wilen for comments on earlier drafts or portions of this work. Excellent research assistance was provided by Nolan Derby, Rui Wan, and Jevan Cherniwchan. The usual disclaimer applies. 


\section{Introduction}

Energy is the most important commodity in the world today. And by almost any metric, the energy industry is impossibly large. Yearly energy sales at over 10 trillion (US) dollars dwarf expenditures on any other single commodity; trade and transport of energy is immense with over 3 trillion dollars in international transactions driving product deliveries through 3.5 million kilometers of pipelines and 535 million deadweight tons of merchant shipping; 7 of the 10 largest global corporations are energy companies; and about a third of the global shipping fleet is occupied shipping energy. ${ }^{1}$

Against this background of facts testifying to the enormity of energy in the world today, stands an energy economics literature that is applied in focus, and often partial equilibrium in nature. ${ }^{2}$ While the literature's decidedly micro-based attention to individual markets has brought us tremendous insight into the workings of many energy markets - one wonders what larger questions concerning energy have been left unanswered as a result?

The purpose of this paper is to introduce a new, and decidedly abstract and aggregative, approach to energy economics to ask how the location and "spatial productivity" of energy resources affects the distribution of economic activity around the globe. This is a large, and as yet unanswered, research question that cannot be resolved by any one paper; instead, we take one small, but important, step towards answering it by developing a bare bones theoretical framework to define "spatial productivity" precisely; to show how differences across both renewable and non-renewable energy resources in their spatial productivity have large effects on supplies; and to link our theory to recent empirical work finding very strong links between the spatial productivity of energy resources and the location of economic activity.

The modeling choices we make are informed by three key observations. The first is that energy is not physically scarce. Many sources of energy available today - solar, wind, coal and non-conventional oil and gas - represent vast, almost limitless, potential supplies. The economic costs of exploiting them however limit their use. The second - amply demonstrated by the facts and figures reported earlier - is that exploiting far flung energy resources and moving energy to markets is primarily what the energy industry does. And the third is a recognition that one of the most important attributes of an energy resource is its ability to deliver substantial power relative to its weight or physical dimensions. ${ }^{3}$

\footnotetext{
${ }^{1}$ See online appendix for sources and methods. https://dl.dropboxusercontent.com/u/83825333/Online.pdf

${ }^{2}$ A short list of important contributions are Borenstein, Bushnell and Wolak (2002), Joskow and Kahn (2002), Salant (1976) and Wolfram (1999).

${ }^{3} \mathrm{~A}$ fourth observation could be the spatial concentration of economic activity around the globe. See Nordhaus (2006) for details and gecon.yale.edu/large-pixeled-contour-globe for a wonderful graphic.
} 
To implement an approach based on these observations we build a very simple spatial model. The economy's core occupies no space, and its location is fixed throughout. The exploitation zones where energy resources can be found are two dimensional planes allowing us to employ definitions of area, distance, and density. Distance is meant to capture any and all costs incurred when incremental amounts of energy are exploited. Timber resources for example may only be available some distance from the core; and for some renewable energies - solar or wind power, or biofuels - measures of area are important to consider. For other energy sources, like fossil fuels, surface area considerations are less important, but here increasing distance can reflect the difficulties firms have in accessing incremental resources due to well depth, non-standard geological formations, hostile weather conditions, etc.

These assumptions eliminate any role for physical scarcity by assuming energy resources are limitless, but still costly to exploit. And since energy resources are located in geographic space, the availability of energy resources at any given location affects deliveries and ultimate supplies elsewhere. In a spatial setting, "availability" reflects spatial productivity; and therefore we introduce a measure of this productivity called power density. While this is not a familiar measure to most economists, it represents the ability of an energy resource to provide a flow of power taking into account the area needed for its exploitation. Despite its current unfamiliarity, we show how power density is determined by very conventional and commonly used measures of resource characteristics: for example it reflects differences in the energy content of available resources (key to fossil fuels), recharge rates (key to many renewables), and yields (important to all staple energy crops).

Putting these assumptions together generates our Only Energy model where the location and power density of available energy resources determines economic outcomes. Since there is but one factor of production and all technologies are constant returns to scale (CRS), relative prices are determined by the supply side alone. Accordingly, we ignore demand entirely and focus on planning solutions that maximize energy supplied to our core. ${ }^{4}$ Although we have not modeled a demand for energy, it should be apparent that for any given demand structure the variations in supply our theory highlights will create strong incentives for economic activity to concentrate in our core. We have three major results.

The first result is that even small differences in the spatial productivity of energy resources have large economic consequences. This comes about from a scaling law that links our

\footnotetext{
${ }^{4}$ We do not model economic activity in the core to focus on the relationship between spatial productivity and the ability of a given environment to deliver power. A general equilibrium interpretation of the model is provided in our web appendix; alternatively, in a companion paper (Moreno-Cruz and Taylor (2012)) we developed a simple two factor general equilibrium model of economic activity and agglomeration building on the basis of the framework we develop here. The first section of this earlier paper was canibalized and then extended to create this contribution.
} 
measure of spatial productivity (power density) to changes in energy supply. We show how the productivity of energy resources together with transport costs determines which resources are exploitable by our core and which resources are stranded. Variation in the productivity of energy resources creates large changes in the set of exploitable resources, and this is the basis for the scaling law.

This scaling law plays out differently for renewables and non-renewables. In the case of renewables, it implies that access to an energy resource twice as power dense delivers eight times the energy supply. Even small differences in the power density of say staple crops or timber resources may have large effects on local populations and economic activity. In the case of non-renewables, we find extractions must at first rise and then fall over time. Peak extractions are increasing in the power density of the resource which suggests a pattern of rapid growth, boom and bust should be relatively common in the fossil fuel era.

Together these results imply economic activity reliant on energy use should be concentrated or bunched. It should be bunched across geographic space when reliant on renewables, and bunched in time when reliant on non-renewables.

Our second result is that power dense energy resources, and investments to increase the set of exploitable resources, are complements. We start by showing how the exogenous introduction of a low cost transportation option effectively magnifies the power density of available energy resources. This equivalence means that placing a road, a river or a transmission line near our core has the same effect as endowing the region with resources of higher power density. The magnification works by extending the exploitation zone for energy resources, and it implies that natural but discrete variation in the landscape created by valleys, rivers, and coastlines make any nearby core appear, and operate, as if it was endowed with far more productive energy resources. Therefore, if economic activity bunches in response to variation in power densities - it bunches in response to variation in these geographic attributes as well.

Next, we show how endowing a region with power dense resources raises the incentives for endogenous investments that extend the exploitation zone. Given our equivalence result, it may not be surprising that these investments can be targeted at reducing transport costs directly for given energy resources (roads, pipelines, transmission lines); or they may be designed to alter the character of energy resources themselves by upgrading (compressing, refining, and raising voltages). Upgraded resources have higher energy content, lower transport costs or both.

Together these results reveal a strong complementarity between infrastructure investments and power dense energy resources. They suggest very few, if any, power dense energy resources will ever be stranded - a point made strongly by features of the energy industry 
we highlighted above - and reveal that the massive trade, transport and upgrading of energy resources we observe today is perfectly explicable if fossil fuels are indeed power dense.

To answer this question we turn to measurement which provides our last major result. Since power is the flow of energy per unit time, typically measured in Watts, power density measures the flow of energy a resource can provide in Watts per unit area needed for its exploitation and maintenance. ${ }^{5}$ In the case of renewables power density comes directly from the area requirement for a resource (say timber or biofuels or solar power), together with its ability to provide a steady state flow of energy measured in Watts. In the case of nonrenewables surface area is still important, but high energy content non-renewable resources are primarily found subsurface, and energy flows now come from the depletion of energy stocks. To make renewables and non-renewables commensurate, we aggregate over the subsurface deposits using the marginal costs of recovery. Using these methods and our theory, we provide a simple decomposition linking the power density of both renewables and nonrenewables to energy contents, to the physical density of resources in the environment, and to their rate of recharge or extraction. We then provide estimates of the power density for various staple food crops, fuel wood, and one fossil fuel. In general we find non-renewables are several orders of magnitude more dense than renewables.

Combining our findings with knowledge of the past suggests that the most salient feature of the history of world energy use in the last two hundred years is the increasing reliance on extremely power-dense energy resources. More speculatively, since these same two hundred years witnessed a rising trend towards urbanization and agglomeration, it is at least suggestive of a potential link between the power density of available energy resources and the geographic concentration of economic activity - much as our theory suggests. While intriguing, this conjecture relies on a yet unproven connection between the power density of local energy resources and measures of economic activity.

To address this point, we discuss three recent empirical contributions that make this connection precise. We suspect there are many such examples, but we choose to focus on these three because they examine the impact of low cost access to widely different energy resources (both renewables and non-renewables), examine energy resources both with and without physical mass (coal versus hydroelectric dams) and take great care in estimating a causal impact. Our discussion argues that these studies report results very supportive of our findings although somewhat shy of a direct empirical test. Moreover, we demonstrate how our theory should inform future research along these lines.

Apart from these direct connections with recent empirical studies, our work is related to

\footnotetext{
${ }^{5}$ Expending one Joule of energy per second provides one Watt of power. Power density is typically measured in Watts per $m^{2}$.
} 
previous contributions in both energy and resource economics, and has benefitted in perhaps less obvious ways from the contributions of economic historians. ${ }^{6}$ Although the Only Energy model is constructed from first principles, it bears some resemblance to von Thunen's model of an Isolated State. In contrast to von Thunen however, transport costs and, by implication, the exploitation zone are set by appeal to physical laws governing energy use. It also bears a family resemblance to other spatial models of resource and energy use where resources and demand centers are treated as points in space (Gaudet, Moreaux and Salant (2001)); where consumers (Kolstad (1994)) or resources (Laffont and Moreaux (1986)) are distributed on line segments; where resource pools are differentiated by costs, suggestive of a spatial setting (Pindyck (1978), Swierzbinski and Mendelsohn (1989), and Chakravorty, Roumasset, and Tse (1997)); and situations where resources themselves move across space (Sanchirico and Wilen (1999)). These contributions are however quite different and focus on very different questions and problems.

The rest of the paper proceeds as follows. In section two we develop a simple model linking power density to energy supply, and show how it applies to renewables with mass (biomass, staple crops), those without mass that produce electiricty (solar, wind), and to non-renewables (fossil fuels). In section three we examine how investments in transport and upgrading can enlarge the exploitation zone. In section four we discuss recent empirical work. A short conclusion ends the paper. We document data sources and provide proofs in the appendix. ${ }^{7}$

\section{The Only Energy Model}

We develop a simple model of energy exploitation where energy is the only input and only output of production. This one factor world makes it easy to introduce our assumptions on geography and costly transport and define power density. Extensions to more than one factor and to market economies are not difficult. ${ }^{8}$ We first consider the case of renewables since it admits a simple steady state analysis and leave the similar, but more complicated, case of non-renewables to Section 2.2.

\footnotetext{
${ }^{6}$ See for example Allen (2009), Wrigley (2010), Smil (2008), and Fouquet and Pearson (1998).

${ }^{7}$ An online appendix shows, among other things, how we can extend our basic model to cover punctiform resources that exist at only a point in space, and resources whose locations are uncertain.

${ }^{8}$ For one such extension see Moreno-Cruz and Taylor (2012).
} 


\subsection{Renewable Resources}

We start with a definition. The area exploited in the collection of energy is related to the power obtained measured in Watts [W], and the power density of the resource measured in Watts per meter squared $\left[\mathrm{W} / \mathrm{m}^{2}\right]$. If the flow of power collected is $W$, and the available energy resource has power density $\Delta$, then the exploitation zone, $E X$, must equal:

$$
E X=W / \Delta
$$

where $E X$ is measured in meters squared $\left[\mathrm{m}^{2}\right]$.

We assume collection is costless, but transport to the core requires the use of energy. ${ }^{9}$ For now, assume transport costs are proportional to distance and energy collected (we will provide conditions under which this will be true subsequently). In this case, all we need to understand is unit costs. To that end, consider energy resources with power density $\Delta$, and let $c / \Delta$ be the energy cost of moving resources representing one Watt of power one meter. If our objective is to maximize energy deliveries to the core we collect energy resources until the marginal resource collected provides no net energy. Denote by $R^{*}$ the distance these marginal resources are from the core. At this margin one Watt collected is now fully expended in costly transportation to the core; that is, $R^{*}$ must satisfy:

$$
1-\frac{c}{\Delta} R^{*}=0 \text { or } R^{*}=\frac{\Delta}{c}
$$

The more power dense are the energy resources, the larger is the circular exploitation zone surrounding our core. ${ }^{10}$ For example, very power dense resources (for the moment, think very dry timber) will be collected at great distances, while energy resources like straw or dung will not. If energy is an essential input then the limits imposed by (2) will in turn constrain economic activity in any core. Therefore, the spatial productivity of energy resources may well have determined the maximal size of human settlements in earlier eras. And even now, when both the numerator and denominator of (2) are under at least partial control, it still provides a useful definition. It simply says that for any given location of the core and transport costs, all resources are either exploitable (within the zone) or stranded (outside of

\footnotetext{
${ }^{9}$ Adding constant per unit extraction costs contributes little except notation to the analysis.

${ }^{10}$ Despite some similarities, our formulation and that of von Thunen are not the same. Whereas we associate any energy resource with a finite region of exploitation tied to its power density, the geometric transport costs of von Thunen - cleverly coined iceberg costs by Samuelson - imply an infinite exploitation zone for any and all energy resources. As a result the iceberg assumption of von Thunen leads to the somewhat uncomfortable implication that we can move a barrel of oil (a cord of wood, a bale of hay, a pound of dung, an Ampere of electricity etc.) a billion miles and still reap some energy resources from it. See our online appendix for a further discussion.
} 
it).

While it is apparent that total power collected is: $W^{*}=\Delta E X=\Delta \pi\left[R^{*}\right]^{2}=\pi \Delta^{3} / c^{2}$, to find the net power delivered to the core we need to subtract the energy costs of transport. This net power supplied comes from adding up, what we will call, "energy rents." These rents are the excess of energy collection over transport; i.e. $\Delta-c r$ at all distances $r \leq R^{*}$ from the core. They are positive for exploitable resources, and zero for stranded resources. To add them we use a two step procedure. Along any ray from the core, there are $\Delta$ Watts of power every meter and transporting these resources to the core yields a density of $[\Delta-c r]$ net Watts of delivered power. The first step is to add up these resources along our ray over all distances less than $R^{*}$. The second step is to accumulate these quantities by sweeping across the $2 \pi$ radians of our circular exploitation zone. By doing so we obtain net power supply to the core as the sum of all energy rents:

$$
W^{S}=\int_{0}^{2 \pi} \int_{0}^{R^{*}} v[\Delta-c \cdot v] d v d \varphi=2 \pi \int_{0}^{R^{*}} v[\Delta-c \cdot v] d v=\frac{\pi \Delta^{3}}{3 c^{2}}
$$

Net power supply is a cubic function of power density. Renewable resources twice as power dense deliver eight times the supply. The implication of this result is immediate: even small variations in the natural landscape affecting the productivity of renewable resources can have large implications for energy supply in any core. For example, suppose the distribution of power densities $\Delta$ over potential locations $f(\Delta)$ was uniform over $[0, \bar{\Delta}]$; then $50 \%$ of the total net energy supplied is concentrated in $12 \%$ of all locations. ${ }^{11}$

To verify that this result reflects a scaling law tied to our spatial setting rather than being an artifact of our circular region of exploitation, we now construct a setting where the exploitation zone is not circular and solve for energy supply. To proceed we assume resources at different locations have different transport costs. This heterogeneity could arise from the nature of the resource, the terrain, etc., and in a later sections we will show how these transport cost differences can arise endogenously. For simplicity, we measure the location of a resource by its direction (in radians) relative to the core. In this more general environment we can now show:

Proposition 1 Scaling Law: If energy resources everywhere have power density $\Delta$ but transport costs vary with the direction $\theta$ so that $c=c(\theta)$, then the exploitation zone is no longer

${ }^{11}$ If $\Delta$ is distributed uniform on $[0, \bar{\Delta}]$ and delivered power is given by $W(\Delta)=\frac{1}{3} \frac{\Delta^{3}}{c^{2}}$, then the probability distribution of power $W$ is given by: $F_{W}(w)=\operatorname{Pr}\{W<w\}=\operatorname{Pr}\left\{\frac{1}{3} \frac{\Delta^{3}}{c^{2}}<w\right\} \cdot \operatorname{This}$ implies $\operatorname{Pr}\{\Delta<$ $\left.\left(3 c^{2} w\right)^{1 / 3}\right\}=\frac{\left(3 c^{2} w\right)^{1 / 3}}{\bar{\Delta}}$. The value $w_{50 \%}$ for which $50 \%$ of the total net energy delivered across all locations solves $F_{W}\left(w_{50 \%}\right)=0.5$. Solving for $w_{50 \%}$ we obtain: $w_{50 \%}=\left(0.5^{3}\right) \bar{W}=0.125 \bar{W}$ where $\bar{W}=\frac{\bar{\Delta}^{3}}{3 c^{2}} \cdot 50 \%$ of the net energy delivered is concentrated in $12.5 \%$ of the locations. 
circular while gross power collected and net power supplied remain homogenous of degree three in $\Delta$.

Proof. See Appendix.

The intuition for this result is easiest to grasp in the simpler case when the exploitation zone is circular. Suppose we increase the power density of available resources, but hold the exploitation zone constant; then supplied power should rise proportionately with power density; i.e. appear with power 1 (recall the definition in (1)). But a higher power density also implies the marginal cost of exploitation falls. Every meter expansion of the exploitation zone garners more resources than before, and hence with lower marginal costs, the extensive margin moves outwards. Since area is proportional to (or scales with) the square of the extensive margin (here the radius), total power from the set of exploitable energy resources rises with the square of power density. Adding up adjustments across both margins, means total power collected, and net power delivered, are both cubics in power density.

While this logic is impeccable, it does however rely on our assumption that energy resources travel at constant costs; and at this point it is not clear exactly why, or for what energy resources, this should be true. The next two sections expand on this assumption.

\subsubsection{Biomass, Wood, and Staple Crops}

We have assumed a constant energy cost $c$ to transport resources, but said very little about why. To understand this assumption, consider the movement of resources with physical mass like biomass, wood, and staple crops. The energy costs of moving these resources amounts to the work done in overcoming friction in land transportation; and since these resources are transported continuously in a steady state this work amounts to Watts of power expended for transport. A useful abstraction, that we will subsequently relax somewhat, is that the transportation network is already in place and available for use without further investments. As a consequence direct transport from any location is possible.

To understand why we assume constant unit energy costs requires a small amount of high school physics. Recall Work is equal to force, $F$, times distance, $x$, or $W_{k}=F \cdot x$. Force is in turn equal to mass, $M$, times acceleration $a$. In our case, the relevant acceleration is the normal force exerted by gravity since any mass moved horizontally must overcome the force of gravity $g$ as mediated by friction in transport where $\mu$ is the coefficient of friction. ${ }^{12}$ This work is done per unit time since power is a flow. And measuring time in seconds, $W_{k}$

\footnotetext{
${ }^{12} \mathrm{We}$ are ignoring static friction encountered when the object first moves. The force that needs to be overcome to keep an object in motion is equal to the normal force times the coefficient of friction. Since the object is moving horizontally, the normal force is just gravity times the mass of the object. The coefficient of friction is a pure number greater than zero; and force is measured in Newtons.
} 
expended in transportation is now Joules per second which represents the Watts expended in bringing resources to the core. ${ }^{13}$

Keeping these results in mind, revisit our unit costs of transport. If the energy resource in question has power density $\Delta\left[\right.$ Watts $\left./ \mathrm{m}^{2}\right]$, then resources capable of providing one watt are contained in an exploitation zone with area $1 / \Delta$. If this resource - think timber or biomass - is available in a quantity $d$ kilograms per squared meter, then these resources must weigh $d / \Delta$ kilograms. And moving these resources one meter while overcoming friction, requires a flow of power of $\mu \mathrm{gd} / \Delta$. Therefore, when energy resources have mass (and they incur land transport costs) we have $c=\mu g d$ which is of course constant. It is now apparent why we have assumed transport costs are linear in distance (work is proportionate to distance) and linear in power collected (work is proportionate to the mass transported).

\subsubsection{Solar Power, Wind Farms, and Electricity}

While constant costs may be a good assumption for some renewables, many of the most common renewable energy sources we use today - wind, solar and hydro - need to be transformed into electricity before they can be used in productive ways. And it is not obvious these resources travel at constant cost. The key observation is that line losses - that is, the power lost in electricity transmission - operate much like our constant energy costs of transport given by $c$. These line losses come from resistivity losses or what the industry calls Joule heating. These losses are the analog of the energy spent in performing work when transporting resources with mass.

In our earlier discussion of energy resources with mass (timber, coal, etc.) we implicitly assumed resources move at constant speed (there was no acceleration of the resource, no inertial friction, and no deceleration either) which seems quite natural given our steady state analysis. The parallel assumption here is that electric power should move at a constant current which we denote by $I$ and measure in Amperes. But just as physical transport costs are linear in distance when objects move at constant speed; line losses are linear in distance when electricity is transmitted at constant current. Therefore, we can once again link our per unit distance transport cost, $c$, to fundamental determinants. Since doing so relies on concepts less familiar to most readers (Ohm's law, definitions of line resistance, etc.) we leave the details to the appendix, and simply assert $c$ is again constant, but now reliant on the current and the transmission line's resistivity as reflected by its material, $\rho$, and its cross sectional area, $a$. In particular, $c=I^{2}(\rho / a)$.

Therefore if solar or wind resources are geographically dispersed then their power density will determine, exactly as before, the net power that could be delivered to the core. And

\footnotetext{
${ }^{13}$ Expending 1 Joule of energy in 1 second means you are delivering 1 Watt of power.
} 
variation in these productivities over space will produce the same sort of bunching in energy supply we described earlier.

\subsection{Non-Renewables: Oil, Gas and Coal}

With the renewable model fully in hand we can now turn to consider the slightly more complicated case of non-renewables. Extending our framework to non-renewables presents several challenges. First, since using non-renewable energy today precludes you from using it tomorrow the exploitation zone must change over time as the resource stock is depleted. This is true because with non-renewables, energy flows come from depleting the resource stock and not from harvesting the perpetual yield from a renewing resource. One simple and natural way to address depletion is to assume ongoing extractions hollow out the exploitation zone as the resource is extracted. ${ }^{14}$

Second, while we can for the most part ignore the potential impact current energy collection has on the future productivity of renewables (harvesting solar power today does not affect the likelihood of sunshine tomorrow), this is not possible with non-renewables. To see why, use the approach discussed above and assume all energy resources up to $r$ have already been extracted. Then, the remaining non-renewable energy that could be supplied to the core is given by:

$$
W^{S}=2 \pi \int_{r}^{R^{*}}(\Delta-c v) v d v=\frac{\pi \Delta^{3}}{3 c^{2}}-\pi\left(\Delta r^{2}-\frac{2}{3} c r^{3}\right)
$$

where $R^{*}=\Delta / c$ as before. The intuition is clear. The economy loses the energy it would have been able to collect over the area already mined - this is, $\pi \Delta r^{2}$ - net of the energy it would have expended to bring this energy to the core, $(2 / 3) \pi c r^{3}$. Previous extractions raise the cost of current extractions, and the key economic problem is to determine the rate we wish to use these resources over time. To address this problem we will assume a time separable CRRA utility function that maps delivered energy into instantaneous utility flows, and maximize the discounted sum of these flows subject to resource availability and costs.

\footnotetext{
${ }^{14}$ There is a small literature examining least cost paths for depletion in situations with multiple deposits or resources. This literature, started by Herfindahl (1967), examines when, and under what conditions, a least cost order of extraction path will be optimal. Chakravorty and Kruice (1994) contains relevant references, some discussion, and a neat result showing the typical least cost path prediction does not hold up when the resources in question are not perfect substitutes in use. This possibility is ruled out in our one energy source set up, but would be relevant in any extension with two, less than perfectly substitutable, resource types.
} 


\subsubsection{A Solow-Wan Reformulation}

In order to solve our intertemporal energy supply problem we start by recognizing that our spatial model with reserves differentiated by location, can be rewritten as a standard problem where there is a fixed and given resource stock exploited subject to rising marginal extraction costs. A similar reformulation was first suggested by Solow and Wan (1976) in an environment where resources were differentiated by their grade, and it proves useful to do so here. ${ }^{15}$

To reformulate the problem along Solow-Wan lines, we first recognize that the exploitation zone has radius $R^{*}=\Delta / c$, and this exploitation zone implies a corresponding limit on recoverable reserves which we denote $\bar{X}$. These recoverable reserves are simply equal to $\bar{X}=\pi \Delta^{3} / c^{2}$ which again reflects our scaling law. But if the current resource frontier is $r(t)<R^{*}$, then the remaining recoverable reserves at $t$, which we denote $X(t)$ must be equal to

$$
X(t)=2 \pi \int_{r(t)}^{R^{*}} \Delta \iota d \iota=\bar{X}-\Delta \pi r(t)^{2}
$$

where $r(0)=0$ since no resources have been extracted at the start of time. Cumulative extractions at $t$, are simply $\Delta \pi r(t)^{2}$.

Differentiating with respect to time, we find the needed link between remaining recoverable reserves and today's rate of extractions:

$$
\dot{X}=-2 \pi r(t) \Delta \dot{r}(t)=-W(t)
$$

The intuition is simple. As extraction proceeds, reserves are drawn down and the resource frontier expands. The frontier expands at rate $\dot{r}(t)$ as resources with power density $\Delta$ are reaped from a ring with density $2 \pi r(t)$ per unit time. The last equality in (6) follows because the instantaneous change in the stock must equal $W(t)$ - the flow of energy extracted at $t$ measured in Watts. This completes the first step of the reformulation.

The second step in the reformulation is to find the associated cost function for extractions. When $W(t)$ is extracted, it is divided between deliveries to the core $W^{S}(t)$ and energy used in transport which we denote $W^{T}(t)$. We refer to these costs as extraction costs. Because at any $t$ there is a unique $r(t), W^{T}(t)$ must equal $r(t)[c / \Delta] W(t)$ and hence $r(t)[c / \Delta]$ represents unit extraction costs. While this is useful, we need to eliminate $r(t)$ and purge the problem of all spatial elements. To do so use (5) to substitute for $r(t)$ as a function of remaining reserves $X(t)$ and total reserves $\bar{X}$. With some simplification, we can now write the relationship

\footnotetext{
${ }^{15}$ Solow and Wan (1976) suggested this reformulation in a short footnote; for a more illuminating treatment see section 2 of Swierzbinski and Mendelsohn (1989).
} 
between energy supplied to the core, $W^{S}(t)$, current extractions, $W(t)$, remaining reserves $X(t)$, and recoverable reserves $\bar{X}$, as:

$$
\begin{gathered}
W^{S}(t)=[1-C(X(t))] W(t) \\
C(X)=\left(1-\frac{X}{\bar{X}}\right)^{1 / 2}
\end{gathered}
$$

where we now interpret $C(X(t)) W(t)$ as the cost of extracting $W(t)$ units of energy from a homogenous pool of recoverable reserves $\bar{X}$, when remaining reserves equal $X . C(X(t))$ is therefore the unit extraction cost function (where we have suppressed its reliance on recoverable reserves, $\bar{X}$ ). With this machinery in place, we can now prove:

Proposition 2 Assume intertemporal utility is of the CRRA form, then the optimal depletion path has extractions rising to a peak and then declining. Peak extractions are rising in the power density of the energy resource.

Proof. See Appendix.

Somewhat surprisingly, extractions must at first boom and then (optimally) bust. This is true despite the uniform distribution of resources across space; despite the very conventional form of intertemporal utility and absence of demand shocks; and despite the absence of learning by doing, technological change or exploration activity. Moreover, the peak in extractions is greater the more power dense the underlying resource. ${ }^{16}$

At bottom the cause is the scaling law linked to the spatial structure of the model but to understand why this is true, we need to understand the two quite different motivations governing optimal depletion. First, and not surprisingly, there are the standard Hotelling motives arising from the finiteness of the resource stock and the impatience of our planner. For example, if the costs of bringing energy to the core was zero (but there remained a finite resource stock available for use), then the shadow value of the resource in situ rises at the rate of time preference. Energy extracted would equal energy supplied to the core and the time profile for extractions would be given by

$$
\frac{\dot{W}(t)}{W(t)}=-\frac{\rho}{\sigma}<0
$$

where $\rho$ is the discount rate, and $\sigma$ the elasticity of marginal utility from the CRRA specification. ${ }^{17}$ Since optimality requires the value of marginal utilities discounted to time zero

\footnotetext{
${ }^{16}$ See Holland (2008) and Boyce (forthcoming) for a related discussion of Peak Oil models.

${ }^{17}$ See the Appendix for details.
} 
to be equalized across all periods, this is achieved by energy consumption falling at a rate proportional to time preference and the elasticity of marginal utility. This motivation follows from the finiteness of the reserves; it predicts a declining path for extractions; and, it reflects the forces identified in Hotelling's classic work (Hotelling 1931).

Second, and less familiar, are what we could call Ricardian motives. These motives come from the fact that reserves differ in their Ricardian rents: energy resources very proximate to the core have large rents and are very scarce; while very distant ones have very little rent but are abundant. Once we translate this feature of our spatial structure - via the Solow-Wan reformulation - into an implication on extraction costs, it implies that differences in Ricardian rent across reserves are now reflected in extraction costs that rise rapidly with cumulative extraction. Since any unit extracted today raises the cost of all future extractions, all else equal, it pays to shift these extraction costs into later periods. These Ricardian motives argue for a delay in extractions or what is the same, a rising path of extractions over time. Ignoring the Hotelling term given above, an extraction path that reflects only Ricardian considerations is given by

$$
\frac{\dot{W}(t)}{W(t)}=-W^{S}(t) C^{\prime}(X)>0
$$

As we show in the appendix, the simple sum of the right hand sides of (9) and (10) guide optimal extractions, and hence the interplay of these two forces produce a boom and bust path for energy production.

Descriptively, the result follows because the Ricardian motivations initially dominate Hotelling considerations. Analytically, it follows because at the very first instant of time, energy consumption must be positive $W^{S}(0)>0$, and $C^{\prime}(X(0))=-\infty$ implying $\dot{W}(t)>0$ at least initially. And as extraction proceeds $W^{S}(t)$ must approach zero (the resource is finite) and $C^{\prime}(X(t))$ increases to a finite bound. Therefore, the Ricardian forces fall over time and are eventually dominated by the Hotelling ones.

More deeply, the impact of using up the very first unit of resources on subsequent extraction costs is so costly, $C^{\prime}(X(0))=-\infty$, not because these initial energy resources have the greatest rents (which they do) but because they are so scarce in relation to the resource pool whose extraction costs are now raised. Scarcity drives the result and high rent resources are so scarce because of our scaling law. ${ }^{18}$ To see why, recall that energy rents fall linearly with distance, but the quantity of reserves rises with the square of distance. This implies low rent resources are abundant, and high rent resources are scarce. Increasing the power density of the energy source raises rents everywhere, but also brings in play new low rent resources at

\footnotetext{
${ }^{18}$ For example, if resources are located only on a one-dimensional line segment, resources close to the core are high rent, but optimal extractions fall throughout. For a proof, see our online appendix.
} 
the margin of exploitation. Consequently, the motivation for pushing extractions into the future is strengthened and the peak of extractions rises.

While it is well known that the typical Hotelling's prediction can be overturned in a variety of settings, the boom and bust in extractions is a necessity in our framework and not a possibility. ${ }^{19}$ Moreover, it follows from our scaling law which has the dual cost implications reflected in (8). The spatial setting provides us with a neat analytical representation for a well known empirical fact: high rent resources are scarce and low rent resources abundant and then suggests that the logical implication of this fact is that both Ricardian and Hotelling motives drive optimal extractions. Ignoring spatial elements and their attendant impact on rents removes a key force driving optimal extractions; and taking them into account suggests an interesting parallel. Non-renewable resource extraction should be concentrated or bunched in time, just as renewables energy extractions should be bunched across space.

\section{Stranded and Exploitable Resources}

We have taken power density as a primitive, and shown how variation in this primitive plays a key role in determining energy supplies. While it is quite natural to think first of variation across space in the productivity of soils, temperature, moisture, etc. as driving differences in power density; it would be naive to ignore the possibility that power density is, to some extent, under our control (selective breeding of crops is just one such example). Similarly we have taken transport costs as given, but they too are choice variables. Since the ratio of these two "primitives" determines which resources are exploitable and which are stranded, the economic incentive to manipulate the power density of an energy resource is closely related to the economic incentive to lower its transport costs. To understand these incentives, we start by asking which energy resources are power dense and why? By doing so we identify the incentive for resource upgrading. We then follow by asking how investments to change the character of the resource to raise its energy content, lower its transport costs, or both are related to its underlying productivity.

\subsection{The Incentive to Upgrade}

We start by providing a decomposition of power density into its component parts to understand how it may be subject to control. The decomposition links power density to directly observable and familiar characteristics such as crop yields, energy contents, and growth rates. We provide a similar decomposition for non-renewables in a subsequent section.

\footnotetext{
${ }^{19}$ The first observation that extractions may boom and bust is often credited to Livernois and Uhler (1987).
} 
To start consider renewables that produce a physical harvest (timber, staple crops, fisheries, etc.) In these cases, we can write the steady state flow of energy harvested in Watts $\mathcal{F}$ [Watts] from the renewable energy resource as the product of three things: the size of the resource stock $S[\mathrm{~kg}]$; its current growth rate $r$ [1/time]; and the energy content of the yield, $e$ [Joules $/ \mathrm{kg}$ ]. $\mathcal{F}=r e S$, where $r S$ represents the physical harvest per unit time, and $e$ translates this physical flow into an energy flow in units of Watts. The physical size of the stock $S$ can in turn be written as the product of the physical density of the resource in the environment, $\delta\left[\mathrm{kg} / \mathrm{m}^{2}\right]$ times the area containing the resource $a\left[\mathrm{~m}^{2}\right]$. Making this substitution we obtain the flow of energy as $\mathcal{F}=($ re $\delta) a$. Power density is just the flow of energy per unit area or $\Delta=\mathcal{F} / a=r e \delta\left[\mathrm{W} / \mathrm{m}^{2}\right] .{ }^{20}$ Therefore, for a renewable resource that generates a continuous physical harvest flow - like a coppiced forest, biomass, etc. - its power density is proportional to its rate of growth, or recharge rate, $r$, its energy content $e$ [Joules $/ \mathrm{kg}$ ], and its physical density in the environment, $\delta\left[\mathrm{kg} / \mathrm{m}^{2}\right]$. Since the harvest from the resource is $r S$ we have $d=r \delta$ as the density of the harvest. Using this result we can now rewrite to find $\Delta=e d$, and $R^{*}=e / \mu g$. This leads to our next proposition.

Proposition 3 Quality versus Quantity. The extensive margin of energy collection is independent of the quantity of the resource available (measured by its physical density in the environment), but proportional to its quality (measured by its energy content).

Proof. In text.

Proposition 3 is quite intuitive. Recall the extensive margin is defined by zero net energy rent resources; that is, those for which transport costs completely dissipate the benefits of collection. Since transport costs are proportional to the amount collected, as is the energy contained within, it matters little whether we have an ounce of these marginal resources or a ton - marginal resources are marginal in whatever quantities we find them.

Once said, this result seems obvious, but it may explain much of the energy resource upgrading we see in the world today or in the past. Consider for example the age old collection of firewood and conversion to charcoal before transport. Charcoal has a higher energy content than wood, and therefore - via Proposition 3 - will be collected at greater distances. The fact that the conversion of fuel wood into charcoal is incredibly inefficient in a physical sense is irrelevant. Since stranded firewood resources have a zero opportunity cost, any degree of inefficiency is acceptable if a conversion to a higher $e$ resource is possible.

\footnotetext{
${ }^{20} \mathrm{~A} 100 \mathrm{~kg}$ forest growing at $10 \%$ per year generates $10 \mathrm{~kg}$ of firewood per year. Firewood contains $15 \mathrm{MJ}$ per kg; and there are $31,536 \times 10^{3}$ seconds in a year. This piece of the forest provides $4.75 \mathrm{~W}$ on average for the year. If the physical density of the forest is such that it contains $50 \mathrm{~kg}$ of trees over each meter squared, then the power density of this forest resource is $(4.75 / 2)$.
} 
Similarly today it is common to see energy resources upgraded to make transportation more efficient (lower $\mu$ ), raise energy content $(e)$, or both. For example, the upgrading of heavy oil not only raises its energy content and lowers its transport cost by lowering viscosity, it is also very energy intensive. While we may bemoan the energy and pollution consequences of this upgrading, the opportunity cost of using stranded resources is very low and hence the logic of doing so is impeccable. Compressing or liquifying natural gas is another example where the energy content (per unit volume) is raised, transportation made easier, and yet the process is quite costly.

Resource upgrading of this form is also common among energy resources without mass that generate electricity (solar, wind, hydro). To see why recall that in this case energy rents are driven to zero at the margin of exploitation, and this occurs at a distance given by

$$
l^{*}=\frac{\Delta}{c}=\frac{\Delta}{I^{2}(\rho / a)} .
$$

Where the extensive margin now varies with power density, amperage and the details of the transmission network. Low amperage raises delivered power as do large lines and better materials. To understand how amperage matters, note that we have assumed any given location throws off power at rate $\Delta$ in Watts but said little about how this power is transmitted. In fact, this power can be transmitted in a variety of ways because current times voltage equals Watts, or $W=V I$. Therefore, for a renewable energy source $x$ with power density $\Delta$ we have a similar decomposition with $\Delta(x)=V(x) I(x)$. Substituting this into (11) we see that the extensive margin for source $x$ is given by:

$$
l^{*}(x)=\frac{V(x)}{I(x)(\rho / a)}
$$

Although voltage and amperage are not innate characteristics of energy sources, unlike energy contents and yields of renewables with mass, it is true that producing power from wind, solar, thermal generation or nuclear sources requires a set of generation technologies that have been optimized to meet their peculiar requirements. These generation technologies differ in the voltage produced. We can therefore think of otherwise homogenous providers of electricity as heterogenous in this regard, and from (12) we know the extensive margin relevant to any particular source $x$ is rising in its voltage of transmission and falling in its amperage.

Putting these results together, we have a result much like we had before. Raising the power density of an energy source raises the flow of power produced but has no impact on the extensive margin if the ratio voltage (quality) to amperage (quantity) remain constant. 
And resources that would otherwise be stranded by their distance or low quality will either remain stranded or call forth endogenous investments to lower costs. While we prefer high voltage transmission (just as we prefer high energy content fuels) because it lowers line losses (or physical transport costs), altering voltage is of course costly just as improving roads, building canals, etc. to improve land transportation is costly. Indeed, our theory suggests that what appears to be excessively wasteful expenditures in energy used to ramp up voltages for the long distance transmission of renewables are but the mirror image of energy intensive methods to upgrade heavy oil or compress natural gas for non-renewables.

\subsection{Roads, Rivers, and Transmission Lines}

Rivers, roads, and canals were all important components of the energy transportation system in the 19th century just as power lines, pipelines, and LNG terminals are important today. What they have in common is that they represent investments made to lower the cost of transport and enlarge the set of exploitable resources much as resource upgrading would do.

To proceed we make three simplifications. First, we start by examining the impact of adding a single low cost transportation option that cuts across the exploitation zone and through our core. Second, we model the investment and maintenance costs needed for infrastructure as flow costs rather than up front sunk investments. Third, we consider only renewable resources. We make these simplifications to limit the set of possible cases while providing natural starting points for future work.

We start by examining the impact of having a river, road or transmission line running through the economic core. All three represent low cost options, but we assume rivers only lower the costs of transporting energy from upstream sources, whereas roads and transmission lines lower energy transportation costs in both directions. Since our analysis is conducted in terms of our generic transport $\operatorname{cost} c$, the analytical results we find are identical for roads and transmission lines. Moreover, because the case of a river is a special case of the road case, we refer to the road problem below and highlight the differences with the river case when necessary.

\subsubsection{The Energy Supplier Problem}

Consider the decision problem of a potential energy supplier located on one meter squared of land with the flow of energy produced equal to $\Delta$ Watts. The supplier can take energy directly into the core or deviate to take advantage of a road nearby. Rivers and roads help to reduce the amount of work used in transportation, increasing the amount of energy delivered to the core. To capture this in our analysis we allow for the unit cost of transportation by 
road to differ from the unit cost of transportation by land by a fraction $\rho<1$. That is, while the cost by land is equal to $c$, the cost by road is $\rho c{ }^{21}$

We assume the road is a straight line that crosses the core and expands indefinitely. The location of a supplier relative to the core is described by two terms: $\iota$, the distance from the core and $\theta$ the angle between the segment formed by the core and the supplier and the road as shown in Figure 1.

We solve the energy producer's problem in two stages. In the first stage transportation costs are minimized by choosing how much distance to cover by land and how much distance to cover by river. In the second stage energy rents are maximized. The cost minimization problem is given by:

$$
\min _{\iota_{1}, \iota_{2}} c \iota_{1}+\rho c \iota_{2}
$$

subject to

$$
\iota^{2}=\iota_{1}^{2}-\iota_{2}^{2}+2 \iota \iota_{2} \cos \theta
$$

where $\iota_{1}$ is the distance travelled by land and $\iota_{2}$ is the distance travelled by road.

The constraint follows directly from the law of triangles with $\iota_{1}$ being opposite to the angle $\theta$, as shown in Figure 1. We can replace the constraint in the objective function to find the optimal distances travelled by land and by road:

$$
\iota_{1}^{*}=\frac{\iota \sin \theta}{\left(1-\rho^{2}\right)^{1 / 2}}
$$

and

$$
\iota_{2}^{*}=\iota \cos \theta-\frac{\rho \iota \sin \theta}{\left(1-\rho^{2}\right)^{1 / 2}} .
$$

If the distance $\iota_{2}^{*}$ is strictly positive, the supplier deviates to the road, otherwise the supplier goes straight to the core. We can solve for the critical value of $\theta$ that separates the suppliers that go straight to the core from those who deviate to the road:

$$
\iota_{2}^{*}>0 \text { if and only if } \theta \leq \cos ^{-1} \rho \equiv \bar{\theta}
$$

Energy suppliers located at any angle $\theta<\bar{\theta}$ are "close" to the low cost alternative and choose to use it. Since $\rho=\cos (\bar{\theta})$ we know that as $\rho \rightarrow 0$ everyone deviates, since it is so cost effective. Alternatively, as $\rho \rightarrow 1$, the road offers no advantage and no one uses it.

The second part of the energy producer's problem is to decide whether or not to take its energy to the core. An energy producer situated a distance $\iota$ from the core and forming an

\footnotetext{
${ }^{21} \rho<1$ can alternatively represent the benefits of transmission at higher voltage, large cables, or better materials.
} 


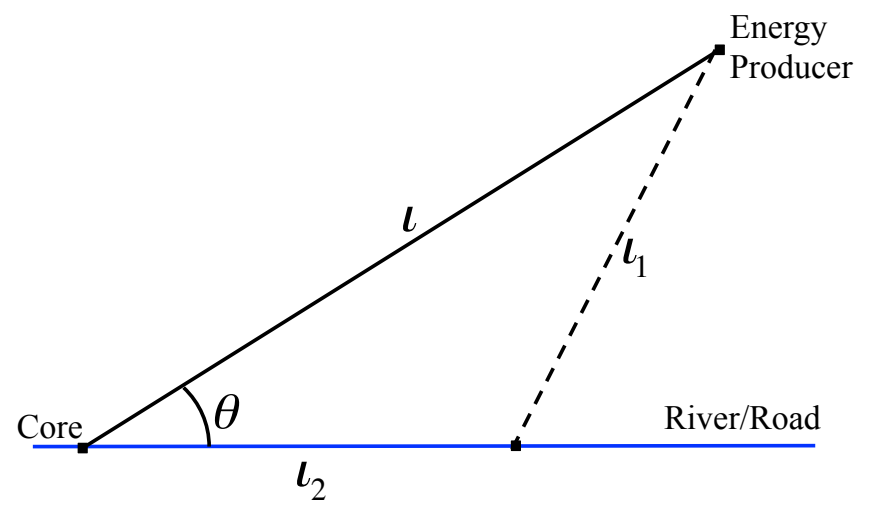

Figure 1: Transport via Road or River

angle $\theta$ with the road will go to the core if the net energy supplied to the core is positive; i.e., if there are positive energy rents at this location. Energy supplied by this producer is given by

$$
W^{S}=\Delta-c\left(\iota_{1}^{*}+\rho \iota_{2}^{*}\right)
$$

Replacing equations (15) and (16) in the previous equation makes energy rents a function of the distance to the core $\iota$. There is a critical distance $\iota^{*}$ at which suppliers become indifferent between bringing their energy to the core or supplying zero. This distance is determined by setting $W^{S}=0$ and it is given by:

$$
\iota^{*}=\frac{\Delta}{c} \begin{cases}\left(\left(1-\rho^{2}\right)^{1 / 2} \sin \theta+\rho \cos \theta\right)^{-1} & \text { if } \theta \leq \bar{\theta} \\ 1 & \text { if } \theta \geq \bar{\theta}\end{cases}
$$

which determines the area of exploitation. The zero rent margin, if the producer does not deviate, is exactly as before. But if the producer finds it useful to use the low cost alternative, energy rents are greater and the zero rent margin further from the core.

At this point it is worth noting that (19) defines an endogenous $c(\theta)$ schedule. $c(\theta)=c$ if $\theta \geq \bar{\theta}$; and

$$
c(\theta)=\left(\left(1-\rho^{2}\right)^{1 / 2} \sin \theta+\rho \cos \theta\right)^{-1} \text { if } \theta \leq \bar{\theta}
$$

Therefore by Proposition 1 we know our scaling holds even when agents choose a cost minimizing path to the core. Although energy suppliers no longer carry their resources over hill and dale directly to the core, their cost minimizing path is only dependent on their location relative to the core as represented by $c(\theta)$. 


\subsubsection{The Magnification Effect}

Just as before, the total energy supplied to the core is found by "adding up" all energy rents.

$$
W^{S}=4 \times\left[\int_{0}^{\bar{\theta}} \int_{0}^{\iota^{*}} v\left(\Delta-c\left(\iota_{1}^{*}+\rho \iota_{2}^{*}\right)\right) d v d \theta+\int_{\bar{\theta}}^{\pi / 2} \int_{0}^{\iota^{*}} v(\Delta-c v) d v d \theta\right]
$$

The first integral represents energy coming from suppliers who are close enough to the road to use it in transport. The second integral represents the energy coming from those who travel directly to the core. We have multiplied the integrals by 4 since we are adding up over the quarter circles of $\pi / 2$ radians.

Integrating and simplifying gives us a net energy supply much like that we had before:

$$
\begin{aligned}
& W^{S}=\frac{1}{3} \frac{\Delta^{3}}{c^{2}} g(\rho) \\
& g(\rho)=\pi-2 \bar{\theta}+2 \int_{0}^{\bar{\theta}}\left(\left(1-\rho^{2}\right)^{1 / 2} \sin \theta+\rho \cos \theta\right)^{-2} d \theta \geqslant 0
\end{aligned}
$$

where the function $g(\rho)$ is positive and monotonic, approaches infinity as $\rho$ goes to zero and approaches $\pi$ as $\rho$ goes to 1 . We depict the exploitation zone in the river and road case in the two panels of Figure 2 assuming $\rho<1 .^{22}$

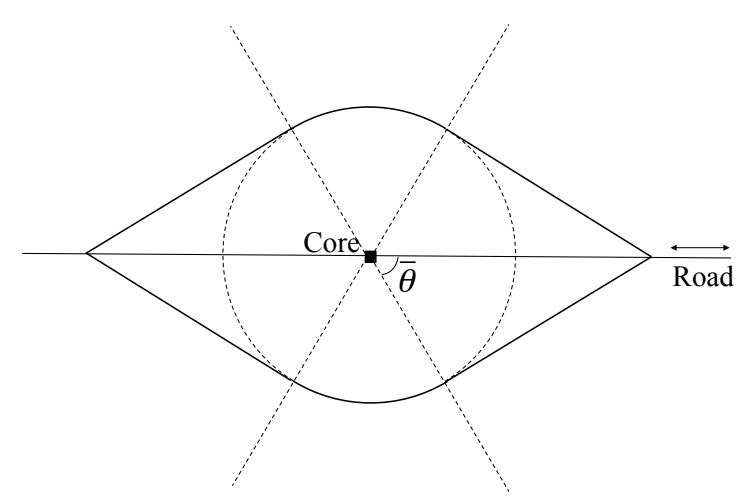

(a) Area of Exploitation with a Road

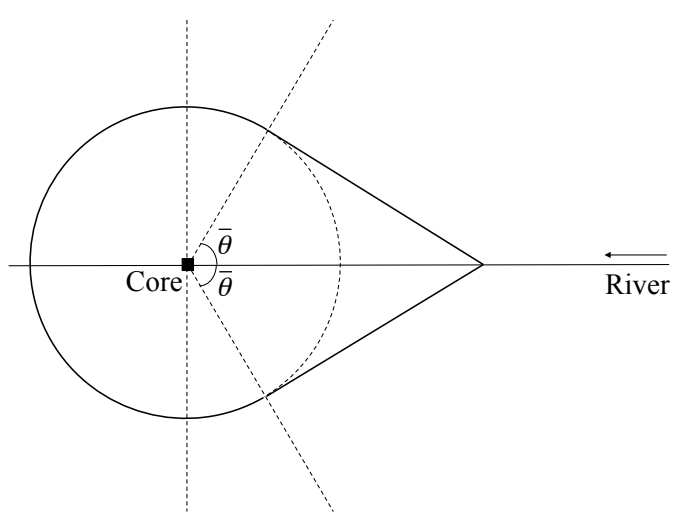

(b) Area of Exploitation with a River

Figure 2: Exploitation with Rivers or Roads

\footnotetext{
${ }^{22}$ When traveling with the current a river's cost is also $\rho c$ but against it $c / \rho$. By this assumption, river transport is only useful when you are an energy producer upstream; whereas road transport reduces frictions in two directions and not one. Thus, we need to modify the gains function: $g_{\text {river }}(\rho)=\frac{\pi}{2}+\frac{g(\rho)}{2}$.
} 
It is useful to redefine terms slightly to rewrite supply as:

$$
W^{S}=\frac{1}{3} \frac{\pi \tilde{\Delta}^{3}}{c^{2}} \text { where } \tilde{\Delta} \equiv \Delta(g(\rho) / \pi)^{1 / 3} \text { and }(g(\rho) / \pi)^{1 / 3} \geq 1
$$

which is exactly the same form as our earlier net supply with a slight redefinition of our power density term. Importantly, because $g(\rho) \geq \pi$ we have proven:

Proposition 4 Magnification. Endowing our core with access to a low cost transportation option is equivalent to endowing its surrounding region with more power dense energy resources.

Proof. In text.

This result implies that as far as energy supply is concerned, having a road or river (or transmission line) cut across the core is identical to being surrounded by more productive energy resources.

Road location multiplies by some factor greater than one, the power density of available resources. This multiplier depends on the cost reducing impact of the transportation option as reflected in $\rho$. Setting $\rho=1$ means the river or road offers no advantage in terms of transportation. This implies $g(\rho)=\pi$ since then $\bar{\theta}=0$ and there is no multiplier of power density. But any $\rho<1$ effectively magnifies the power density of available resources; and letting $\rho$ approach zero implies $g(\rho)$ approaches infinity and energy is no longer economically scarce.

A moment's reflection will reveal that regardless of the number, and regardless of the efficacy of additional (straight line) transportation options we introduce, the endogenous solution for energy supply delivered to the core, will again satisfy our scaling law. This is true, since by Proposition 1 all cost minimizing paths are just different particular solutions for $c(\theta)$. Moreover, if we were to add additional roads through our core these options can only reduce costs (given optimization), and the equivalence result we report in Proposition 3 is strengthened. Every one of these additional transportation improvements is equivalent to, in energy supply terms, an additional increase in the power density of surrounding resources. With a small bit of work it can be shown that if we were to add any number of identical low cost transportation options and locate them optimally, then:

Proposition 5 Energy supply to the core is an increasing and weakly concave function of the number of transportation options serving it.

\section{Proof. See Appendix.}

The observable implication is that locations blessed with many transport options look like they are endowed with very power dense energy resources. 


\subsection{Energy Investments}

The magnification effect tells us two quite useful things. The first is that access to low cost transport options is equivalent to raising the power density of surrounding resources. Given this equivalence, for any investment lowering the physical cost of transport there is an equivalent one raising the power density of energy resources by upgrading. Upgrading resources and investing to lower transport costs are opposite sides of the same coin, and by understanding the incentives for one we understand the incentives for both. Therefore we consider only investments to lower transport costs in the text, and leave a similar parallel analysis to footnotes where appropriate.

The second is that the marginal impact of low cost transport options is greater for more power dense resources. This is apparent from (22) and it tells us the energy supply consequences of say river access is far higher in a world run by, for example, coal than it would be in one run on biomass. This suggests that investments to lower transport costs will be greatest in situations where energy resources are already quite power dense.

To examine the motivation for energy investments assume the cost of building and maintaining transport that delivers an efficiency of $\rho$ is given by $h(\rho) .{ }^{23}$ Assume $\rho>\bar{\rho}$ where $\bar{\rho}$ is the minimum physically possible value of the coefficient of friction. Since a lower value of $\rho$ implies lower cost energy transport we assume $h(\rho)$ is a decreasing and convex function: $h^{\prime}(\rho)<0, h^{\prime \prime}(\rho)>0$ with $h(1)=0$ and $h^{\prime}(1)<0$. Then energy supplied net of infrastructure costs are $W^{N}=W^{S}(\rho)-h(\rho)$. For concreteness consider the case where $W^{S}(\rho)$ is given by equation (20) and we are improving river transportation by dredging, locks, canals, maintaining ports etc. The optimal investment problem is simply given by

$$
\max _{\rho} W^{N}=W^{S}(\rho)-h(\rho)=\frac{1}{3} \frac{\pi \Delta^{3}}{c^{2}} g(\rho)-h(\rho)
$$

When the solution is interior, the first order condition that maximizes energy requires

$$
\frac{1}{3} \frac{\pi \Delta^{3}}{c^{2}} g^{\prime}(\rho)=h^{\prime}(\rho)
$$

\footnotetext{
${ }^{23} \mathrm{We}$ could proceed in the same way to calculate the optimal investment on upgrading of resources. Upgrading resources is equivalent to increasing power density, $\Delta$. Recall that for the case of renewables with mass we have $\Delta=e d$. The examples discussed above in the text suggest that the role of upgrading is increasing energy content $e$, while taking concentration $d$ as given. With this in mind, power supplied to the core is given by $W^{S}(e, d)=\frac{1}{3} \frac{\pi e^{3} d}{(\mu g)^{2}}$. Next, consider a function $k(e)$ such that $k^{\prime}(e)>0$ and $k^{\prime \prime}(e)>0 . k(e)$ captures the costs of increasing the energy content of a resource. With this information, we can follow the steps presented in (23) and (24) to show that improving transportation or upgrading resources (by increasing energy content) are equivalent problems from the perspective of the energy producer.

It also follows from the equivalence between electricity transmission lines and roads that increasing transmission voltage, therefore reducing Joule losses, is equivalent to reducing $\rho$ which reduces land friction and transportation loses.
} 
The lefthand side of this equation is the marginal benefit from improved transport and it is again a cubic in power density showing a strong relationship between power density and the marginal benefit of further investments. The right hand side is simply marginal costs of improved transportation. Since marginal benefits are bounded and marginal costs of the first unit of investment are positive, with sufficiently low power density no investments in transport improvements will occur. In situations with higher power density an interior solution will obtain and we can write the implicit solution to $(24)$ as $\tilde{\rho}(\Delta)$. Straightforward differentiation now shows ${ }^{24}$

$$
\frac{d \rho}{d \Delta}=-\frac{\rho}{\Delta} \frac{3}{\epsilon_{h \rho}^{\prime}-\epsilon_{g \rho}^{\prime}}<0
$$

where $\epsilon_{h \rho}^{\prime}=-\rho h^{\prime \prime}(\rho) / h^{\prime}(\rho)$ and $\epsilon_{g \rho}^{\prime}=-\rho g^{\prime \prime}(\rho) / g^{\prime}(\rho)$ and the second order conditions sign the expression. ${ }^{25}$ Therefore, we have proven:

Proposition 6 Complementarity. There exists a critical level of power density $\Delta^{c}>0$ such that for energy resources with $\Delta<\Delta^{c}$ no investments in cost reducing transport occur; but for environments with $\Delta>\Delta^{c}$, investment is positive and more power dense energy resources call forth greater investments in cost reducing transportation investments.

Proposition 6 links the incentive for transport and upgrading of resources to their power density. Resources with low power density will neither be upgraded nor call forth large investments to improve transportation. Biomass for example is not a very power dense energy resource, and in a world run on biomass we should expect very local energy markets that are severely constrained by transport costs. These local markets could be expanded somewhat by simple upgrading (charcoal), but the incentives for dedicated investments should be weak. With the advent of fossil fuels new incentives arose. More power dense fuels like coal brought forth large investments in lowering transport costs and upgrading. Canals, railroads, and upgrading coal to coke could be seen as endogenous responses to its higher power density. In the petroleum era we have witnessed and continue to witness today, massive investments in pipelines, tankers and terminals, so that the set of exploitable petroleum resources now includes oil drilled in the world's most inhospitable Arctic climates and is collected from underwater wells literally miles deep. Naturally given the distances involved

\footnotetext{
${ }^{24}$ We have already assumed $h^{\prime \prime}(\rho)>0$; it can be shown that $g(\rho)$ is convex for all values of $\rho$. The second order conditions required for a maximum imply $\frac{1}{3} \frac{\pi \Delta^{3}}{c^{2}} g^{\prime \prime}(\rho)<h^{\prime \prime}(\rho)$ which simply says the costs are more convex than the benefits from investing in infrastructure.

${ }^{25}$ For the case of resource upgrading, the optimization problem is given by $\max _{e} W^{N}=W^{S}(e, d)-k(e)=$ $\frac{1}{3} \frac{\pi e^{3} d}{(\mu g)^{2}}-k(e)$. The first order condition is given by $\frac{\pi e^{2} d}{(\mu g)^{2}}=k^{\prime}(e)$. Finally we can totally differentiate the first order condition to obtain: $\frac{d e}{d d}=\frac{e / d}{\epsilon_{k e}^{\prime}-2}>0$, where $\epsilon_{k e}^{\prime}=e k^{\prime \prime}(e) / k^{\prime}(e)$ and the sign follows from the assumption that costs are more convex than the benefits from upgrading resources.
} 
and the distribution of resources around the world, energy shipments now routinely cross political boundaries which has created a huge international trade in energy products where two centuries previous there was virtually none at all. Proposition 6 links this long chain of events to the changing power density of available energy sources. ${ }^{26}$

\section{Empirical Application and Evaluation}

The theory we developed makes several sharp predictions. To transfer these very abstract predictions into their implications for empirical work it is useful to step back and examine the role cheap energy plays in market economies.

The first effect is simply the direct impact cheap energy has on firm costs, production, profits and, over the longer term, entry. If low energy costs are reliant on close proximity to an energy source (because of transportation costs), then this direct impact will tend to concentrate economic activity close to the cheap energy source. This is the concentration motive, and it is the only motivation captured by our theory. Economic activity concentrated in a region because of cheap energy, may however disappear if the original stimulus of cheap energy is removed. Therefore, the concentration motive is potentially fleeting and surely will be if the resource in question is non-renewable.

The second effect of cheap energy is agglomeration. If the original concentration of activity leads to thick consumer, producer, and labor markets, then additional economic activity may be stimulated as firms and laborers are attracted by the benefits thick markets bring. In contrast to the concentration motive, the agglomeration of economic activity in a region may be self sustaining long after the attraction of cheap energy is gone. Therefore the agglomeration motive has potentially permanent effects. ${ }^{27}$

These observations imply that the distribution of economic activity we observe in the world today may reflect a complex mix of these forces. They imply that cheap energy sources from the distant past may have produced permanent centers of economic activity that today are very distant from current energy supplies. In others cases, locally cheap energy resources may have produced a boom and bust pattern of development, because agglomeration never took hold. Since the world economy has employed many different energy sources, over many centuries, we will have to identify a set of well documented case studies that trace through the long run impacts of energy shocks.

\footnotetext{
${ }^{26}$ Notice that this analysis can be expanded to the case of electricity generation and transmission. Increasing voltages is costly but reduces line loses, therefore there is an incentive to invest for as long as the power delivered is enough to compensate for the investment in higher voltage lines.

${ }^{27}$ For a recent review of the relevant theory and empirics of agglomeration economies see Head and Mayer (2004)
} 
If we are to use these case studies as litmus tests of our theory we should keep in mind our theory's three, potentially observable, implications. The first is our scaling law: holding other features of a location constant (its access to rivers, roads, or transmission lines), changes in the power density of available resources should produce large changes in energy supply and, via the concentration motive, large changes in economic activity. The second is our magnification effect. Access to low cost transportation options effectively magnifies the energy resources available for use in the core: holding constant the energy resource in question, variation in transport costs will create, via the concentration motive, large changes in economic activity. The third is our finding of complementarity. The incentives to invest in building infrastructure to lower the cost of transport is rising in the power density of energy resources. Low density sources create no new investments; high density sources may create extensive networks.

\subsection{Introduction of the Lowly Potato}

To uncover, and measure the strength of, the concentration motive it would be ideal if we could observe a large energy shock where the underlying resource was very costly to transport (implying the shock has a strong local impact); where its impact was geographically distinct (giving us treatment and control units); and, where its transport costs remained high over time (ensuring the impact had long term effects). Recent work by Nunn and Qian (2011) linking the diffusion of the potato (a very power dense staple crop) to population and urban growth in the Old World fits these requirements exactly.

Nunn and Qian (2011) provides empirical evidence linking the introduction of the potato, from the New World to the Old, to higher population levels and urbanization rates in the Old World. They motivate their work by providing estimates of the number of acres of farmland required to provide 42 megajoules of energy per day for an annual crop cycle of one year (42 megajoules represents a caloric budget of 10,000 calories per day for a family of two adults and three children). Their data on crop yield and energy content is reproduced here in the first three columns of Table 1 below. In column 4 we report our own calculations for the corresponding power densities, and in column 5 present marginal impacts discussed below.

Nunn and Qian use the estimates of the caloric payback per acre shown in Table 1 (column three) to argue the introduction of the potato could have large effects on incomes, and via this channel populations and urbanization rates post 1700 in the Old World. Their baseline empirical estimates suggest a $1 \%$ increase in the amount of land suitable for potatoes in a country raises the urban share of its population by .36\%; and overall, the introduction of the potato is responsible for $26 \%$ of the increase in Old World populations from 1700 to 1900 . 
Table 1: Crop Yields and Power Density

\begin{tabular}{lccccc}
\hline \hline Crops & $\begin{array}{c}\text { Yield } \\
\text { per acre } \\
\mathrm{kg}\end{array}$ & $\begin{array}{c}\text { Energy } \\
\text { Content } \\
\mathrm{MJ} / \mathrm{kg}\end{array}$ & $\begin{array}{c}\text { Acres of land needed } \\
\text { to provide 42MJ per } \\
\text { day for one year }\end{array}$ & $\begin{array}{c}\text { Power } \\
\text { Density } \\
\mathrm{W} / \mathrm{m}^{2}\end{array}$ & $\begin{array}{c}\text { Increased } \\
\text { Power } \\
\%\end{array}$ \\
\hline Wheat & 650 & 13.69 & 1.7 & .07 & 10.75 \\
Barley & 820 & 13.90 & 1.4 & .08 & 10.26 \\
Oats & 690 & 13.47 & 1.6 & .07 & 11.57 \\
Potatoes & 10,900 & 2.92 & 0.5 & .24 & - \\
\hline \hline
\end{tabular}

Notes: To obtain column 4 we transform $42 \mathrm{MJ}$ per day to Watts and Acres to meter. Suppose the number in column 3 is $Z$ acres per $42 \mathrm{MJ}$ per day. Then we have $\frac{42 M J}{\text { Zacres-day }}=\frac{42 M J}{\text { Zacres-day }} \times \frac{1 \text { day }}{24 * 60 * 60 \mathrm{sec}} \times \frac{1 \text { acre }}{4047 m^{2}}$ which canceling units is now in Watts $/ \mathrm{m}^{2}$.

To obtain column 5 we use the numbers we found in column 4 and replace them in equation (25); where $w$ stands for wheat, oats, and barley and $p$ for potato. Then we calculate the energy supplied by each of the wold crops given by $W_{w}^{S}=\frac{\pi \Delta_{w}^{3}}{3 c_{w}^{2}}$. The number reported in column 5 is $1-W_{w p}^{S} / W_{w}^{S}$.

Their identification strategy exploits both the cross-sectional and time series variation in the data by comparing population density in geographic units before and after the introduction of the potato, across units that are more or less, suitable for potato cultivation. This is a perfect experimental design for examining our theory's prediction that variation across space in power density creates large impacts on energy supply and hence economic activity. Table 1 provides evidence that potatoes are indeed a power dense energy source relative to other staples; and their empirical results support Proposition 1's prediction that the spatial distribution of power dense energy resources can have large effects on the distribution of economic activity.

While Nunn and Qian find large effects, are they too small for a world governed by our scaling law? Column four shows the potato is at least three times more power dense than competing staples. In a simple Malthusian set up where available energy per capita is fully dissipated by population growth, we would expect a proportionate response in the population to the change in net energy. ${ }^{28}$ If we combine these observations, should population have grown by $3^{3}$ ? Our theory suggests not. Only if the two crops yields (or $d$ ) are identical and we are considering a complete replacement should net energy rise according to our scaling law. Table 1 in fact shows the yield of potatoes is more than ten times higher than other staples. Since staples are renewables with mass we have $c=\mu g d$ and $c^{2}$ is in the denominator of (3). Using the figures from Table 1 and assuming the costs of transportation are similar

\footnotetext{
${ }^{28}$ For example, in the simplest Malthusian set up we would have population growth equal to births minus deaths. Suppose births $=b_{0}+b_{1}\left(W^{S} / L\right)$; deaths $=d_{0}-d_{1}\left(W^{S} / L\right)$; all parameters are positive and $d_{0}>b_{0}$; then the steady state population is $L=\left[\left(d_{1}+b_{1}\right) /\left(d_{0}-b_{0}\right)\right] W^{S}$ and steady state population densities in a region should be proportionate to net energy delivered by staples.
} 
for all staples ( $\mu g$ is the same across them) shows that net energy delivered by planting only potatoes is predicted to be less than the net energy delivered by planting only wheat. While this is somewhat disconcerting, the potato is unlikely to have displaced competing staples entirely in regions where both could be grown. To see why, we graph in Figure (3) the energy rents associated with the potato and wheat (with subscripts $\mathrm{p}$ and w) using the figures from Table 1. Recall energy rents are $\Delta-c r$ for a generic resource $r$ meters from the core. As Table 1 shows, the potato has much higher power density, but much lower energy content. This means its very high energy rents drop off quickly as shown. Wheat is entirely different, it offers smaller energy rents close to the core, but relatively higher rents further out. The point where the two schedules intersect is given by

$$
r^{*}=\frac{\Delta_{p}-\Delta_{w}}{c_{p}-c_{w}}>0
$$

which is positive. Maximizing net energy means exploiting both resources (if possible) and we can calculate the net energy collected taking into account this optimal crop selection. Denoting this $W_{w p}^{S}$ we find:

$$
W_{w p}^{S}=\frac{\pi \Delta_{w}^{3}}{3 c_{w}^{2}}+\frac{\pi\left(\Delta_{p}-\Delta_{w}\right)^{3}}{3\left(c_{p}-c_{w}\right)^{2}}
$$

The total energy delivered to the core is the sum of the energy provided with Wheat alone (the first term) plus the marginal impact from the potato (the second term). In a situation such as this, the introduction of the potato represents a positive energy shock given by the marginal impact. It is now possible to see how large this marginal impact is using the figures in Table 1. In column 5 of Table 1 we report the percentage change to net energy when the potato is added to an existing energy mix of either wheat, barley or oats. Implicit in these calculations is that a calorie is a calorie, crop selection is determined by maximizing energy rents and not palate considerations, and transport methods are identical for all crops $(\mu g$ is common). As shown, the percentage changes in net energy are now much smaller than an original $3^{3}$ calculation may have suggested, although they do ignore the much greater impact the potato would have created in regions (or periods of the year) where it was the only crop grown.

The introduction of the potato to the Old World provides an excellent case study of a very localized energy shock. Nunn and Qian's empirical strategy identifies an impact arising from the geographic variation in the power density of available staples and finds large effects on local populations. While this work is not a formal test of Proposition 1 it provides suggestive evidence in its favor. Our theory provides other insights as well. Proposition 


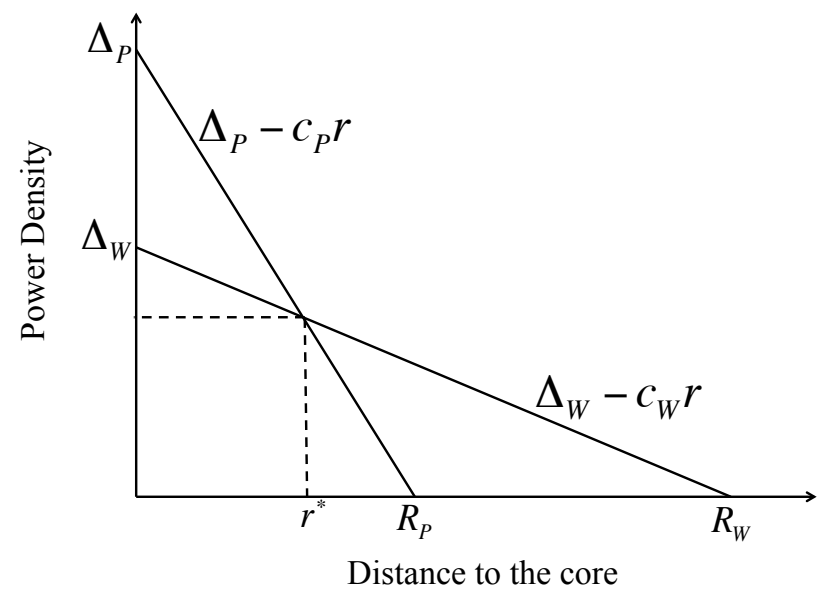

Figure 3: Wheat and Potato Energy Rents

2 in particular suggests the low caloric content but high yield of the potato makes it the perfect local energy shock since long distance transport is not profitable. As well we have shown that the marginal impact of a new energy source depends on the characteristics of the existing mix of energy since new sources only rarely completely replace old ones. Combing our theory with this recognition suggests an alternative empirical strategy where treatment effects (arising from an energy shock) vary not only with the ability of the region to support the new source (potatoes) but also its ability to support earlier energy sources (other staples). ${ }^{29}$

\subsection{Coal and the Industrial Revolution}

While Nunn and Qian (2011) provide excellent evidence on the impact of a local energy shock, their work is necessarily silent on the potentially important role played by transport costs which is highlighted in our theory. Fortunately, recent work by Fernihough and O'Rourke (2014) exploits variation in transport costs to identify the impact of a similar energy shock. These authors study the introduction of coal using technology (primarily steam and smelting innovations) and link these introductions to changes in European city

\footnotetext{
${ }^{29}$ Nunn and Qian come very close to this strategy. In some specifications fixed effects for the ability to grow other staples is interacted with unrestricted time dummies. This would allow the impact during the treatment period to adjust via these coefficients to capture the marginal impacts shown above. It would also, however, require a different interpretation and calculation of the counterfactuals.
} 
populations during the Industrial Revolution. ${ }^{30}$ To do so the authors exploit both across city variation in access to coal (by a distance to coal measure) and over time variation (before and after the innovations diffused). They find that the ability to use coal (in these uses) was responsible for over 60\% of the growth in European city populations from 1750 and 1900. Moreover, local access was found to be very important with a doubling of distance to coal implying a $25 \%$ reduction in its impact on city populations. These are provocative new results that again tie the location of new energy sources to subsequent growth in economic activity, and they too provide largely supportive evidence for our theory. To move past "largely supportive" to strong evidence in favor we need to demonstrate that coal is indeed a very power dense resource; and secondly, that variation in transport costs are expected to have large impacts in our theory.

To start consider transport costs. The authors exploit variation in a city's distance to coal to capture the intensity of treatment. In terms of our theory, their empirical design corresponds to a situation where the type of energy is being held constant but distance is being varied and this should impact energy supply. Given our CRS transport costs, a doubling of distance to the core is equivalent, in energy rent terms, to a doubling of unit costs $c$ holding distance constant. And from (3), a doubling of $c$ lowers net energy supply four fold. Therefore, variation in the distance to energy works much like variation across energy resources in power density. This general point was already apparent from our earlier equivalence result and the resulting magnification effect.

Next consider coal's power density. The method we presented earlier to calculate the power density of renewables cannot be applied directly because non-renewables are obviously very different. For example, the flow of energy obtained from non-renewables is proportional to the change in the resource stock over time, and non-renewables are not spread over vast areas but instead found in subsurface deposits of considerable thickness. To proceed we deal with these issues in turn. First, assume the resource was distributed uniformly on the surface of a two dimensional plane. Then the change in the resource stock would equal the physical flow of the resource, which we will denote by $\phi\left[\mathrm{kg} / \mathrm{m}^{2} \cdot \mathrm{s}\right]$, times the area exploited, $a\left[\mathrm{~m}^{2}\right]$. This gives us the kilograms mined per second. Multiplying by energy content implies the power density of a non-renewable resource distributed on the surface, could be written

\footnotetext{
${ }^{30}$ Moreno-Cruz and Taylor (2012) argue that the shift in England from biomass based fuels to coal in the latter part of the sixteenth century was at least partially responsible for the radical shift in the population distribution across the country. In this earlier work we extend the Only Energy model to incorporate a motive for agglomeration coming from increased specialization. We then wed this model with Malthusian population dynamics and migration to make both population size and its geographic distribution sensitive to proximate energy resources in a county. Using this theory and simple statistics, we argue that access to this very power dense energy resource altered the distribution of population across counties as the energy transition spread across England.
} 
as:

$$
\begin{aligned}
& W=e \phi a \\
& \Delta=W / a=e \phi
\end{aligned}
$$

This makes perfect sense: the flow of energy comes from the change in a stock; the magnitude of the resulting energy flow is determined by the stock's energy content; the change in the stock is equal to the product of the area extracted times the physical flow of the resource mined; and dividing by area exploited, we obtain the result. For future purposes it is also useful to note that the zero rent margin for this non-renewable is again equal to $R^{*}=e / \mu g$ since $\phi \mathrm{kg}$ of the ore is being transported for each square meter mined per second; and hence $c=\mu g \phi$. Therefore, we have a quality/quantity result similar to Proposition 2.

Unfortunately, this measure of power density only holds in situations where non-renewables are distributed very thinly across Earth's surface. For example, shallow deposits of the non-renewable peat may well fit this description. In the vast majority of cases however nonrenewables are not thinly distributed as surface deposits. To tackle this problem we need to develop an appropriate measure of available resources in subsurface deposits. Energy resources will be brought to the surface and then transported to the core only if they provide positive energy rents; and this implies there is now an extensive margin of exploitation for any mine in terms of depth. In the appendix we show resources at all depths above $e / g$ earn positive energy rents if brought to the surface; and these resources when brought to the surface just represent, in essence, a greater density of energy resources at that point. It is as if they are now surface resources that provide a flow $\phi$ per meter, and a power density $\Delta$ as given below.

$$
\Delta=e \phi \text { where } \phi=e d_{v} / 2 g
$$

where $e$ and $g$ are as defined before, while $d_{v}$ is the volumetric density of the resource in $\left[\mathrm{kg} / \mathrm{m}^{3}\right]$.

We now use this formula to calculate the power density for different types of coal in Table 2 below. The formula above assumes a uniform distribution of resources, but in reality deposits differ in terms of depth, quality of coal, and thickness. To give an idea of the resulting power densities we present a set of alternative estimates. We present estimates assuming a deposit's thickness, $h$, is either 1 or 10 meters; estimates for deposit depths, $h_{0}$, of 0 and 10,000 meters; and since coal varies in quality due to the influence of time and pressure we present estimates for a precursor (peat), low quality brown lignite coal; and higher quality bituminous coal.

As shown, higher quality coal has both higher energy content and greater volumetric 
Table 2: Power Density of Different Coals

\begin{tabular}{c|c|c|c|c|c|c}
\hline \hline \multirow{2}{*}{ Resource } & Energy & Volumetric & \multicolumn{3}{|c}{ Power Density $\left[\mathrm{GW} / \mathrm{m}^{2}\right]$} \\
\cline { 4 - 7 } & Content & Density & \multicolumn{2}{|c|}{$h_{0}=0 \mathrm{~m}$} & \multicolumn{2}{c}{$h_{0}=10000 \mathrm{~m}$} \\
\cline { 4 - 7 } & {$[\mathrm{MJ} / \mathrm{kg}]$} & {$\left[\mathrm{kg} / \mathrm{m}^{3}\right]$} & $h=1 \mathrm{~m}$ & $h=10 \mathrm{~m}$ & $h=1 \mathrm{~m}$ & $h=10 \mathrm{~m}$ \\
\hline Anthracite & 33 & 1400 & 46.2 & 462 & 46.2 & 462 \\
Bituminous & 33 & 913 & 30.1 & 301 & 30 & 300 \\
Lignite & 16 & 865 & 13.8 & 138 & 13.8 & 138 \\
Peat & 14 & 310 & 4.34 & 43.4 & 4.31 & 43.1 \\
\hline \hline
\end{tabular}

density. Time and pressure increase both and this implies given our formula that higher quality coal is significantly more power dense than its precursor peat. We find the deposit depth has little effect on the energy contained in the mine, and hence comparing the power density of resources at zero depth versus those at 10,000 meters reveals only small differences. And finally, the power densities are very large. To understand the scale of the energy shock created by a movement to coal we compare these figures with similar figures for wood. We use the methods developed previously for renewables and present in Table 3 estimates for a set of representative forests. In particular, we use data on sustainably managed forests in the United States. As shown, the power densities in Table 3 are very small, providing less than one Watt of power (sustainably) per meter squared.

Table 3: Power Density of Wood

\begin{tabular}{lccccc}
\hline \hline Forest Region & $\begin{array}{c}\text { Total Acres } \\
(1,000 \mathrm{~s})\end{array}$ & $\begin{array}{c}\text { Ave. Prod. } \\
\left(\mathrm{ft}^{3} \text { /acre/yr }\right)\end{array}$ & $\begin{array}{c}\text { Percent } \\
\text { Softwood }\end{array}$ & $\begin{array}{c}\text { Percent } \\
\text { Hardwood }\end{array}$ & $\begin{array}{c}\text { Average } \\
\text { Power Dens. } \\
\left(\mathrm{W} / \mathrm{m}^{2}\right)\end{array}$ \\
\hline Northeast & 79,803 & 57.10 & $25.21 \%$ & $74.79 \%$ & 0.10 \\
North Central & 84,215 & 66.54 & $18.72 \%$ & $81.28 \%$ & 0.12 \\
Southeast & 85,665 & 80.22 & $41.00 \%$ & $59.00 \%$ & 0.14 \\
South Central & 118,364 & 84.69 & $35.20 \%$ & $64.80 \%$ & 0.15 \\
Rocky Mountain & 70,969 & 52.00 & $90.29 \%$ & $9.71 \%$ & 0.08 \\
Pacific Coast & 75,197 & 81.71 & $89.01 \%$ & $10.99 \%$ & 0.12 \\
\hline \hline
\end{tabular}

Note: Data are shown in the Online Appendix.

Several observations are in order. First, a naive comparison of the figures in these tables reveals large differences in power densities which naturally suggests the introduction of coal would be a massive energy shock to an economy where wood provided most thermal energy. While we believe that this was indeed the case, a comparison of these figures requires careful attention. The power densities measured for renewables represents the flow of power we capture on our one square meter of space ad infinitum. The wind blows, the sun shines, crops grow and forests mature providing a potential, and constant in steady state, flow of 
energy we can reap. In the case of non-renewables, the energy flow depends on how fast we extract the resources contained in one square meter. A straight ahead comparison of power densities across these tables implicitly assumes we are consuming all of the non-renewable energy resources from one square meter (and all of its subsurface deposits) per second. This is incredibly fast. A better interpretation of the differences in power densities across these tables is that the potential for reaping power from non-renewables is just vastly greater.

A second observation is that any existing low cost transportation option has a bigger impact on energy supplies when the resource is more power dense. This is an implication of (22) which shows the magnification effect is larger for already power dense resources. Therefore, existing rivers and roads would magnify the impact of coal far more than they magnified the impact of biomass resources.

Third, any comparison of wood and coal using just energy contents will severely underestimate the impact of a move to coal. Coal offers perhaps $25 \mathrm{MJ} / \mathrm{kg}$ while wood $15 \mathrm{MJ} / \mathrm{kg}$, which means we would be willing to transport coal further than wood given similar transport technologies, but not much further. But comparisons like these miss an important point captured in the complementarity effect of Proposition 6. Because coal is so much more power dense, the incentive for expanding the existing exploitation zone is much larger. And it was these endogenous improvements (canals, railroads, ports) in response to coal that combined with its power density to create a huge and long lasting energy shock.

Putting these findings together supports the view that new steam technologies and metallurgical uses for coal would have unleashed a huge energy shock as Fernihough and O'Rourke (2014) claim. The empirical findings show the impacts of coal were geographically distinct given large transport costs, and the estimated changes in urbanization and populations are again very large. However, since the observed changes in economic activity following a shock of this magnitude will reflect both the direct changes created by the concentration motive, plus the knock-on effects created by both complementary investment in transportation infrastructure and the impact of agglomeration, this work does not present evidence on the strength of the concentration motive per se. It does however provide further evidence that the spatial distribution of power dense energy resources can have large effects on the distribution of economic activity.

\subsection{Local Economies and Hydroelectricity}

Neither of the contributions discussed so far divides the impact of "energy shocks" into that caused by the concentration motive (which we model here) and that caused by agglomeration motives (which we do not). However, the treatment periods in these studies cover hundreds 
of years, and hence the impacts measured must surely reflect both the concentration and agglomeration motives. In a very recent paper Severnini (2013) provides us with a method to divide these overall impacts into their concentration and agglomeration components. Important for us is that Severnini's estimates of the total impact arising from the concentration motive alone is large. If a similar division were to hold for the impact of the potato and coal, then the concentration motive for economic activity in those instances would also be significant.

Severnini (2013) examines the impact of hydroelectric dam building on local communities throughout the U.S from 1920 to 1980. A hydroelectric dam in a specific location represents a very power dense energy source; and its placement is an energy shock much like those studied by other authors. He exploits a recent study of hydro potential in the U.S. to develop an experimental design where treated counties had dams built, whereas counties with equivalent potential (but no dam) represent untreated counties. Using a sophisticated synthetic control and event study methodology, he finds the impact of dams on county population growth is considerable and long lasting.

One of the novel features of this study is that it compares the economic impact of dams built before and after widespread access to high voltage transmission lines and thermal generation. In a world without transmission capacity (or cheap thermal generation as a substitute), a dam represents a purely local energy shock that creates both a concentration motive and an agglomeration motive for economic activity. ${ }^{31}$ In a world with transmission lines (and cheap thermal capacity), the local impact of the dam in terms of cheap power is now dissipated by the opportunity to sell power in distant markets, and the ability to provide competing power using thermal generation. As a result, a dam built post 1950 should have little to no impact via the concentration motive and by implication spur no agglomeration.

By exploiting this logic, Severnini is able to divide the full economic impact of an energy shock into the concentration and agglomeration motives. His estimates suggest that dams built post 1950 produce very little new economic activity; dams built prior to 1950 provide large gains (population density increased 51\% over 30 years and $139 \%$ after 60 years for counties treated with dams prior to 1950); but once we enter the post 1950s era with cheap alternatives the benefits of a dam fall considerably. Using the pre and post 1950s growth for treated counties, he estimates that approximately one half of the economic gains of a dam is due to cheap local power or what we have called here the concentration motive.

Looking across all three studies, we find consistent evidence that proximity to a powerful energy source creates large increases in economic activity. While many other studies have

\footnotetext{
${ }^{31}$ Indeed he provides evidence that the price of electricity was $45 \%$ lower in counties treated with a dam relative to control prior to 1950 .
} 
examined the correlation of existing resource stocks to trade flows, growth or other measures, what makes three studies examined here unique is their careful attention to issues of causality. Each presents a clever experimental design combining both cross-sectional and over time variation in unique ways to estimate the impact of energy shocks. While none represent a formal test of our theory's predictions, their results largely echo the three major implications of our theory. Proximity and high power density drive the potato's large impact on populations; variation in distance and hence transport costs created the differential impact of coal resources on subsequent European city growth; and the creation and then removal of the advantages of cheap local power via hydro dams and transmission capacity suggests that perhaps one half of the economic gains coming from an energy shock arise from concentration motives alone.

\section{Conclusions}

This paper set out a simple spatial model in order to ask how the location and spatial productivity of energy resources affects the distribution of economic activity around the globe. This is a very large and as yet unanswered research question, and we have made an admittedly modest but we think significant step towards its answer. Our major contribution is the introduction of a new spatial approach to energy economics where elements from both renewable and non-renewable resource economics are incorporated into a simple, albeit stylized, model of energy use and production. This unity is provided by focussing on the common output produced by both non-renewables and renewables - power- and by going back to the fundamentals of work, force, power and resistance to understand at a very basic level how physical differences across energy resources and their geographic location, can affect deliveries of energy across space. The cost of this unity is that the reader is asked to consider new terms, recall old definitions, and suffer through a seemingly obsessive focus on units that is uncommon to most of economics. The benefits can be summed up in three results: a scaling law, the magnification effect, and complementarity.

We find our spatial setting implies a scaling law. It implies that natural variation in the spatial productivity of renewable energy resources will produce concentrations or bunching in potential energy supplies at different locations. Even a uniform distribution across space will generate a very skewed distribution of potential energy supplies across possible locations. When energy comes from non-renewables, the scaling law implies a different type of bunching. We find that all new non-renewable resource plays must first boom and then (optimally) bust, which implies that extractions are now bunched in calendar time. In total the scaling law tells us that concentrations in economic activity, either across space or across calendar time, 
can arise for very simple reasons.

We find that roads, rivers and other low cost transportation options effectively magnify the power density of available resources. This magnification effect can turn what appears to be a resource poor region into a resource rich one. Therefore, having a road, river or transmission line cross an economic core provides an energy supply equivalent to endowing the region with far more power dense energy resources. Therefore, discrete natural variations in geography like rivers, valleys and coastlines create their own magnification effects providing an energy-centric explanation for much of the location of economic activity we see in the world today.

Finally, while our energy system today is extremely complex and features an incredible transport of energy from producers to consumers that suggests a focus on the locations and productivity of energy resources may be misplaced, we turn this logic on its head by showing how the incentive to create such an infrastructure relies on the existence of power dense energy sources in the first place. By using ideal measures of power densities derived from our theory we show that non-renewables are often 4 or 5 orders of magnitude more power dense than renewables. The implication is that since purposeful investments in transportation improvements and resource upgrading are complementary with resources of greater power density, the fossil fuel era's vast transportation network may be the cause of the diaspora in economic activity we observe in the world today rather than its effect.

While our theoretical results are clear, the implications we have drawn for real world data are both speculative and far reaching. Whether these implications are borne out by future empirical work guided by our theory is impossible to know, but a simple litmus test is available. At bottom all of these results hinge on there being strong relationships between the power density of available resources, the supply conditions for energy they create, and resulting economic activity (which we do not model). To address this deficiency we reviewed three recent empirical studies which examined empirical relationships between the availability of power dense energy resources, and the location of economic activity. These studies examined both renewable and non-renewable energy sources, spanned nearly a millenia in their observation periods, and each devised clever empirical strategies to reliably estimate a causal relationship. While none offer a formal test our theory, we believe all provide strong support for our overall approach. 


\section{$6 \quad$ References}

Allen, Robert C. 2009. "The British Industrial Revolution in Global Perspective." UK: Cambridge University Press

Boyce, J.R. "Prediction and Inference in the Hubbert-Deffeyes Peak Oil Model." The Energy Journal, forthcoming.

Borenstein, S. J. Bushnell, and F. Wolak. 2002. "Measuring Market Inefficiencies in California's Restructured Wholesale electricity market." The American Economic Review, 92(5): 1376-1405.

Chakravorty, U. and D.L. Kruice. 1994. "Heterogenous Demand and Order of Resource Extraction." Econometrica, 62(6): 1445-1452.

Chakravorty, U., J. Roumasset, and K. Tse. 1997. "Endogenous substitution among energy resources and global warming." Journal of Political Economy, 195: 1201-1234.

Fernihough, A. and K.H. O'Rourke. 2014. "Coal and the European Industrial Revolution", National Bureau of Economic Research Working Paper No. 19802j.

Fouquet, R. and R. Pearson. 1998. "A Thousand Years of Energy Use in the United Kingdom." The Energy Journal, 19(4): 1-41.

Gaudet, G., M. Moreaux, and S.W. Salant. 2001. "Intertemporal Depletion of Resource Sites by Spatially Distributed Users." American Economic Review, 91(4): 1149-1159. Head, Keith and Thierry Mayer 2004. "The Empirics of Agglomeration and Trade" Chapter 59 in Handbook of Regional and Urban Economics, Volume 4 edited by J.V. Henderson and J.F. Thisse, Elsevier B.V.

Herfindahl, O.C. 1967. "Depletion in Economic Theory." In Extractive Resources and Taxation, edited by Mason Gaffney, 63-90. Madison, Wisconsin: University of Wisconsin Press.

Holland, S.P. 2008. "Modeling Peak Oil." The Energy Journal, 29(2): 61-79.

Hotelling, H. 1931. "The Economics of Exhaustible Resources." Journal of Political Economy, 39(2): 137-175.

Joskow, P. and E. Kahn. 2002. "Quantitative Analysis of Pricing Behavior in California's Electricity Market During the Summer 2000." The Energy Journal, 23(4): 1-35.

Kolstad, C.D. 1994. "Hotelling Rents in Hotelling Space: Product Differentiation in Exhaustible Resource Markets." Journal of Environmental Economics and Management, 26: $163-180$.

Laffont, Jean-Jacques and Moreaux, Michel. 1986. "Bordeaux Contre Gravier: Une Analyse par les Anticipations Rationnelles," in Gerard Gaudet and Pierre Lasserre, eds., Ressources naturelles et theorie economique. Quebec: Presses de l'Universite Laval, 1986, 
pp. 231- 53 .

Livernois, J.R. and R.S. Uhler. 1987. "Extraction Costs and the Economics of Nonrenewable Resources." Journal of Political Economy, 95(11): 195-203.

Moreno-Cruz, J. and M.S. Taylor. 2012. "Back to the Future of Green Powered Economies," The National Bureau of Economic Research, Working Paper No: 18236.

Nordhaus, W. D. 2006. "Geography and Macroeconomics: New Data and New Findings," Proceedings of the National Academy of Sciences (US), 103(10): 3510-3517.

Nunn, N. and N. Qian. 2011. "The Potato's contribution to population and urbanization: evidence from a historical experiment." Quarterly Journal of Economics, 126, 593-650.

Pindyck, R.S. 1978. "The Optimal Exploration and Production of Nonrenewable Resources." Journal of Political Economy, 86(5): 841-861.

Severnini, E.R. "The Power of Hydroelectric Dams: Agglomeration Spillovers", Working Paper at Carnegie Mellon University.

Salant, S. 1976. "Exhaustible Resources and Industrial Structure: A Nash-Cournot Approach to the World Oil Market," The Journal of Political Economy, 84(5): 1079-1093.

Sanchirico, J.N. and J.E. Wilen. 1999. "Bioeconomics of Spatial Exploitation in a Patchy Environment." Journal of Environmental Economics and Management, 37:129-150.

Smil, V. 2008. Energy in Nature and Society: General Energetics of Complex Systems. USA: MIT Press.

Smulders, S. and E. van der Werf. 2008. "Climate policy and the optimal extraction of high- and low-carbon fossil fuels," Canadian Journal of Economics, 41(4):1421-1444.

Solow, R.M. and F.Y. Wan. 1976. "Extraction Costs in the Theory of Exhaustible Resources." The Bell Journal of Economics, 7(2): 359-370.

Swierzbinski, J.E. and Mendelsohn, R. 1989. "Exploration and Exhaustible Resources: The Microfoundations of Aggregate Models." International Economic Review, 30(1): 175186.

Wolfram, C.D. 1999. "Measuring Duopoly Power in the British Electricity Spot Market." The American Economic Review, 89(4): 805-826.

Wrigley, E.A. 2010. Energy and the English Industrial Revolution. Cambridge, U.K.: Cambridge University Press. 


\section{A Proofs to Propositions}

\section{A.1 Proof to Proposition 1:}

If transportation costs vary with the direction $\theta$, then we can identify the maximum radius

in each direction $\theta$ as $R(\theta)=\frac{\Delta}{c(\theta)}$. To show that gross power is homogeneous of degree 3 we calculate the following integral:

$$
W^{*}=\int_{0}^{2 \pi} \int_{0}^{R^{*}(\theta)} r \Delta d r d \theta=\frac{\Delta^{3}}{2} \int_{0}^{2 \pi} \frac{1}{c(\theta)^{2}} d \theta
$$

which shows that for any function $c(\theta)$ gross power is a function homogeneous of degree 3 in power density. To show the same is true for power supplied, we have to add the energy rents $\Delta-c(\theta) r$ over all the farmers located a distance $r$ away from the core in any direction $\theta$.

$$
W^{S}=\int_{0}^{2 \pi} \int_{0}^{R(\theta)} r(\Delta-c(\theta) r) d r d \theta=\int_{0}^{2 \pi} \frac{R(\theta)^{2}}{2}\left(\Delta-\frac{2}{3} R(\theta) c(\theta)\right) d \theta=\frac{\Delta^{3}}{6} \int_{0}^{2 \pi} \frac{1}{c(\theta)^{2}} d \theta
$$

This shows power supplied $W^{S}$ is homogeneous of degree three in power density, while the precise form of the exploitation zone is determined by the form of $c(\theta)$.

\section{A.2 Proof to Proposition 2:}

A social planner maximizes the welfare of a representative consumer who values the energy services available for consumption in the core. By choosing service units appropriately, utility is defined over net energy supplied. The planner has a CRRA instantaneous utility function with coefficient of relative risk aversion equal to $\sigma>0$. Social welfare is:

$$
\max _{W(t)} \int_{0}^{\infty} e^{-\rho t} U\left(W^{S}(t)\right) d t \text { where } U\left(W^{S}\right)=\frac{\left(W^{S}\right)^{1-\sigma}-1}{1-\sigma}
$$

The planner maximizes (A.1) subject to the constraints (6) and (7). We write the current value Hamiltonian as

$$
\mathscr{H}=U[(1-C(X(t))) W(t)]-\lambda(t) W(t)
$$

where $\lambda(t)$ is the co-state variable associated with the stock of resources. The optimality conditions are given by:

$$
\frac{\partial \mathscr{H}}{\partial W(t)}=U^{\prime}\left(W^{S}(t)\right)(1-C(X(t)))-\lambda(t)=0
$$




$$
\frac{\partial \mathscr{H}}{\partial X(t)}=-U^{\prime}\left(W^{S}(t)\right) C^{\prime}(X) W=\rho \lambda(t)-\dot{\lambda}(t)
$$

with transversality condition $\lim _{t \rightarrow \infty} e^{\rho t} \lambda(t) X(t)=0$.

Using the definition of the utility function in (A.1) and taking the time derivative of (A.3), substituting in (A.4), and rearranging we find one differential equation linking the current rate of extractions to cumulative extractions:

$$
\frac{\dot{W}(t)}{W(t)}=-\frac{\rho}{\sigma}-C^{\prime}(X) W^{S}(t)
$$

A second differential equation is provided by (6) while one initial condition and the transversality condition close the system.

The behavior of the dynamic system is presented in Figure 4 . The $\dot{W}(t)=0$ isocline is depicted by the solid curve in Figure 4. This curve is positive for values of $X(t) \in[0, \bar{X}]$ and has a maximum value when cumulative extraction is one quarter of total reserves; i.e. with remaining reserves $X(t)=3 \bar{X} / 4$ and cumulative extraction $\bar{X}-X(t)=\bar{X} / 4$. The $\dot{X}(t)=0$ isocline is coincident with the horizontal axis. At all points above the $\dot{X}(t)=0$ isocline, movement must be rightwards to extract all reserves, giving arrows of motion in the positive direction parallel to the horizontal axis. At points above the $\dot{W}(t)=0$ isocline, extractions must be increasing since costs are currently too low; below the isocline just the opposite is true. This information is captured by the arrows of motion shown. Assume we

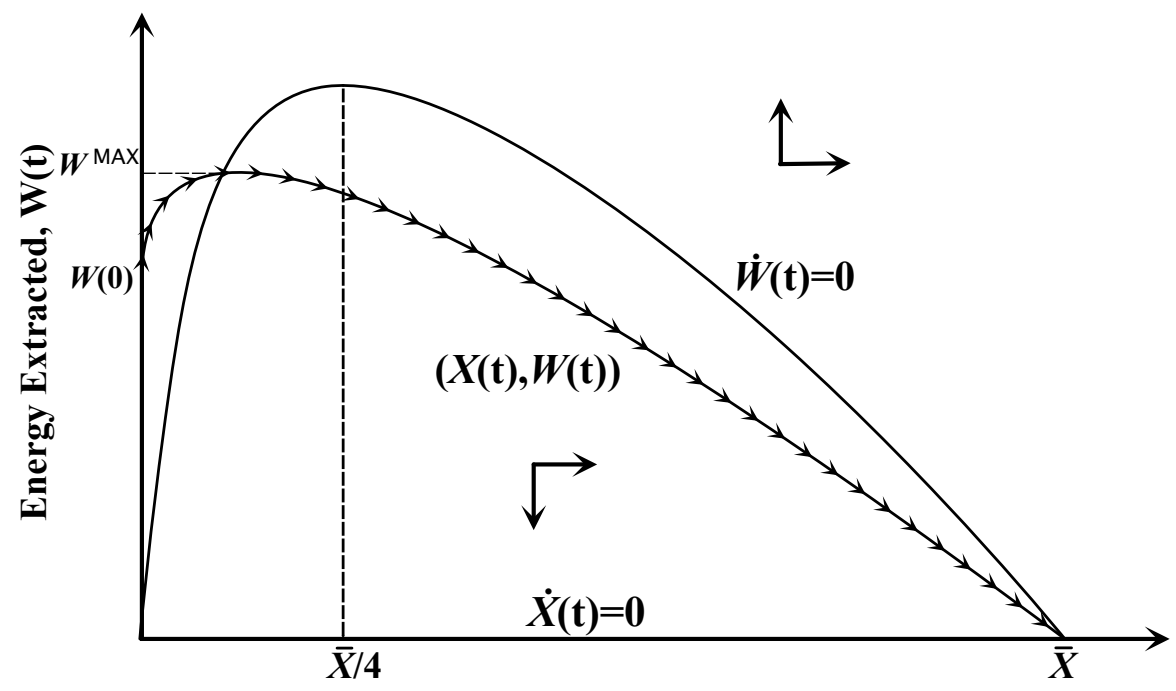

Cumulative Extraction, $X-\bar{X}(\mathbf{t})$

Figure 4: Optimal Extraction Rule

start with a new resource and hence cumulative extractions are zero. Since the arrows of 
motion near the origin imply all movement must be upwards and to the right, we know the system must move immediately to an initial extraction point like that shown by $W(0)=W_{0}$. From this initial point, the arrows of motion indicate we move upwards and to the right and cut the $\dot{W}(t)=0$ isocline at zero slope. Once we cross this isocline, the arrows of motion tell us the extraction path must turn downwards and the transversality condition requires the path slowly approach $\bar{X}$ on the horizontal axis. Working backwards it is now apparent the transversality condition chooses the initial $W_{0}$ and this choice has to feature less extraction than that given by the peak of the $\dot{W}(t)$ isocline. This completes the proof that the optimal extraction path first increases and then decreases.

Next, we show that the peak in the production path increases with power density. That is, for any $Z=\bar{X}-X$ constant, $W^{M A X}$ is increasing in $\bar{X}$. Setting $d W / d X=0$ we find

$\frac{\partial W}{\partial \bar{X}}=2 \frac{\rho}{\sigma} Z \frac{\left(\bar{X}^{1 / 2}-Z^{1 / 2}\right)-\frac{1}{2} \bar{X}^{1 / 2}}{\left(\bar{X}^{1 / 2}-Z^{1 / 2}\right)^{2}}$. Therefore, $\frac{\partial W}{\partial \bar{X}}>0$ if $\frac{\bar{X}}{4}>(\bar{X}-X)$ which always holds as the peak in the extraction always occurs to the left of the peak in the $\dot{W}=0$ locus.

\section{A.3 Proof to Proposition 5:}

Assume all roads have the same coefficient of friction $\rho \mu$ with $0<\rho<1$. Optimal deployment of the road system requires roads are built to maximize coverage. That is, roads will split the space in equal parts. The first road, as we have assumed, would split the space in $\pi$ radians, then second road would split it in $\pi / 2$ radians, the third road in $\pi / 3$ radians, and goes on as we increase the number of roads. Let $n$ denote the number of roads. For given $\rho$, if $n<\bar{n}$ where $\bar{n} \equiv \frac{\pi}{2 \arccos (\rho)}$ then the exploitation zones added by each road do not overlap. If $n>\bar{n}$ the exploitation zones will overlap. For $n<\bar{n}$ we have:

$$
W^{S}=4 \times\left[n\left[\int_{0}^{\bar{\theta}} \int_{0}^{\iota^{*}} v\left(\Delta-c\left(\iota_{1}^{*}+\rho \iota_{2}^{*}\right)\right) d v d \theta+\int_{\bar{\theta}}^{\pi / 2 n} \int_{0}^{\iota^{*}} v(\Delta-c v) d v d \theta\right]\right]
$$

where we have exploited symmetry in the first quadrant of the cartesian space. The integral is then given by:

$$
W^{S}=\frac{1}{3} \frac{\Delta^{3}}{c^{2}} g(\rho, n), \text { where } g(\rho, n)=\pi-2 n \bar{\theta}+2 n \int_{0}^{\bar{\theta}}\left(\left(1-\rho^{2}\right)^{1 / 2} \sin \theta+\rho \cos \theta\right)^{-2} d \theta
$$

It is easy to see now that power supplied is linear in the number of roads, $n$. For $n>\bar{n}$, the exploitation zones will intersect at odd multiples of $\pi / 2 n$. The expression for power supplied 
is now given by:

$$
\begin{aligned}
& W^{S}=4 \times\left[n\left[\int_{0}^{\frac{\pi}{2 n}} \int_{0}^{\iota^{*}} v\left(\Delta-c\left(\iota_{1}^{*}+\rho \iota_{2}^{*}\right)\right) d v d \theta\right]\right] \\
& W^{S}=\frac{1}{3} \frac{\Delta^{3}}{c^{2}} g(\rho, n), \text { where } g(\rho, n)=2 n \int_{0}^{\frac{\pi}{2 n}}\left(\left(1-\rho^{2}\right)^{1 / 2} \sin \theta+\rho \cos \theta\right)^{-2} d \theta
\end{aligned}
$$

To show that power supplied is increasing and concave in the number of transportation options when $n>\bar{n}$ we take derivatives with respect to $n$ and show

$\frac{\partial W^{S}}{\partial n}=\frac{2}{3} \frac{\Delta^{3}}{c^{2}}\left[\frac{g(\rho, n)}{2 n}-\frac{\pi}{2 n}\left(\left(1-\rho^{2}\right)^{1 / 2} \sin \frac{\pi}{2 n}+\rho \cos \frac{\pi}{2 n}\right)^{-2}\right]>0$ and $\frac{\partial^{2} W^{S}}{\partial n^{2}}=-\frac{\pi^{3}\left(\sqrt{1-\rho^{2}} \cos \left(\frac{\pi}{2 n}\right)-\rho \sin \left(\frac{\pi}{2 n}\right)\right)}{4 n^{5}\left(\sqrt{1-\rho^{2}} \sin \left(\frac{\pi}{2 n}\right)+\rho \cos \left(\frac{\pi}{2 n}\right)\right)^{3}}$ which negative when $\sqrt{1-\rho^{2}} \cos \left(\frac{\pi}{2 n}\right)-\rho \sin \left(\frac{\pi}{2 n}\right)>0$ or $n>\frac{\pi}{2 \arccos (\rho)}$.

\section{B Unit Costs of Electricity Transmission}

Electric power measured in Watts is equal to the product of voltage and current: $W=V I$ where $V$ is voltage measure in Volts and $I$ is current measured in Amperes. Volts times Amperes is Watts and since the power flowing from any energy resource will be measured in Watts we need to write line losses in these terms to find net power available for delivery to the core.

When electricity is transmitted over any distance, the transmission line heats up as power is lost to heat because of the line's resistance (Joule heating). Resistance is in turn related to the size, material and length of the line. Very simply resistance is given by $R=(\rho / a) l$ where $\rho$ is a measure of the resistivity of the material used in the cable, $a$ is the cross-sectional area of the cable and $l$ is its length. Therefore, losses due to resistance are simply linear in distance much as frictional losses were linear in distance. To find the extent of losses as a function of distance we need to transform line resistance (which is measured in Ohms) into Watts. To do so we use another well known result from physics: Ohm's law. This law states that the current transmitted along a linear conductor is proportional to voltage and inversely proportional to the resistance; that is, $I=V / R$. Using this law we can now calculate the power dissipated by resistance. Denote the line losses from transmission by $W^{L}$. These losses can then be related to the voltage and amperage relevant to our line as given by $W^{L}=V I$. Now using Ohm's law we can substitute out voltage $(V=I R)$ to find line losses $W^{L}$ are proportional to both resistance and the square of current since $W^{L}=I^{2} R$. Replacing the expression for resistance we have $W^{L}=I^{2}(\rho / a) l=c l$; where $c=I^{2}(\rho / a)$. 


\section{Measuring Power Density for Non-Renewables}

Consider a hypothetical resource owner with resource rights to one meter squared of surface area in our exploitation zone of homogenous resource quality. If this resource owner extracts a $1 \mathrm{~m}^{3}$ cube of energy resources with energy content $e[\mathrm{~J} / \mathrm{kg}]$ and volumetric density $d_{v}\left[\mathrm{~kg} / \mathrm{m}^{3}\right]$, then this cubic meter has mass of $d_{v}[\mathrm{~kg}]$ and weight of $d_{v} g[\mathrm{~N}]$. The total energy contained in this cube would be simply $e d_{v}[\mathrm{~J}]$ and if it was exhausted in one second the power delivered would be $e d_{v}$ [Watts].

Now consider resources contained beneath this $1 \mathrm{~m}^{2}$. If resources are located at distance $\eta[\mathrm{m}]$ from the surface, then the work needed to bring them to the surface would be just $g d_{v} \eta[J]$ since work must be done to offset gravity. Energy rents in this case are just $e d_{v}-g d_{v} \eta$. Resources where the energy cost of extraction equals their entire energy content produce zero energy rents and are located at depth $\eta^{*}=e / g$. The net energy available must account for the energy costs of extraction and is found by the following simple integration.

$$
\Delta=\int_{0}^{\eta^{*}}\left[e d_{v}-g d_{v} \eta\right] d \eta=\int_{0}^{\eta^{*}} e d_{v}[1-(g / e) \eta] d \eta=e^{2} d_{v} / 2 g
$$

To calculate the power density of different deposits we suppose the upper limit of the deposit is located at a distance $h_{0}$ from the surface and the thickness of the deposit is $h$, so the maximum depth of the deposit is $h_{0}+h$. Because the resource rights are over one meter

squared the dimensions of the deposit are simply $\mathrm{h}\left[\mathrm{m}^{3}\right]$. In this case to measure the power density of this deposit, we use:

$$
\Delta=\int_{h_{0}}^{\min \left\{h_{0}+h, \eta^{*}\right\}}\left[e d_{v}-g d_{v} \eta\right] d \eta=\min \left\{h\left[d_{v} e-g d_{v}\left(h_{0}+h / 2\right)\right], e^{2} d_{v} / 2 g\right\}
$$

